\title{
Biovalorisation of crude glycerol and xylose into xylitol by oleaginous yeast Yarrowia lipolytica
}

\author{
Ashish A. Prabhu' ${ }^{1 \dagger}$, Dominic J. Thomas ${ }^{1 \dagger}$, Rodrigo Ledesma-Amaro², Gary A. Leeke ${ }^{3}$, Angel Medina', \\ Carol Verheecke-Vaessen ${ }^{1}$, Frederic Coulon ${ }^{1}$, Deepti Agrawal ${ }^{4}$ and Vinod Kumar ${ }^{1 *}$ (D)
}

\begin{abstract}
Background: Xylitol is a commercially important chemical with multiple applications in the food and pharmaceutical industries. According to the US Department of Energy, xylitol is one of the top twelve platform chemicals that can be produced from biomass. The chemical method for xylitol synthesis is however, expensive and energy intensive. In contrast, the biological route using microbial cell factories offers a potential cost-effective alternative process. The bioprocess occurs under ambient conditions and makes use of biocatalysts and biomass which can be sourced from renewable carbon originating from a variety of cheap waste feedstocks.
\end{abstract}

Result: In this study, biotransformation of xylose to xylitol was investigated using Yarrowia lipolytica, an oleaginous yeast which was firstly grown on a glycerol/glucose for screening of co-substrate, followed by media optimisation in shake flask, scale up in bioreactor and downstream processing of xylitol. A two-step medium optimization was employed using central composite design and artificial neural network coupled with genetic algorithm. The yeast amassed a concentration of $53.2 \mathrm{~g} / \mathrm{L}$ xylitol using pure glycerol (PG) and xylose with a bioconversion yield of $0.97 \mathrm{~g} / \mathrm{g}$. Similar results were obtained when PG was substituted with crude glycerol (CG) from the biodiesel industry (titer: $50.5 \mathrm{~g} / \mathrm{L}$; yield: $0.92 \mathrm{~g} / \mathrm{g}$ ). Even when xylose from sugarcane bagasse hydrolysate was used as opposed to pure xylose, a xylitol yield of $0.54 \mathrm{~g} / \mathrm{g}$ was achieved. Xylitol was successfully crystallized from PG/xylose and CG/xylose fermentation broths with a recovery of 39.5 and $35.3 \%$, respectively.

Conclusion: To the best of the author's knowledge, this study demonstrates for the first time the potential of using $Y$. lipolytica as a microbial cell factory for xylitol synthesis from inexpensive feedstocks. The results obtained are competitive with other xylitol producing organisms.

Keywords: Glycerol, Xylose, Yarrowia lipolytica, Biotransformation, Xylitol

\section{Background}

The development of green technologies is highly desired to stabilise the progressive depletion of non-renewable fossil-derived chemicals [1]. The bio-refinery concept is

\footnotetext{
*Correspondence: Vinod.Kumar@cranfield.ac.uk

${ }^{\dagger}$ Ashish A. Prabhu and Dominic J. Thomas contributed equally to this work

${ }^{1}$ School of Water, Energy and Environment, Cranfield University, Cranfield MK43 OAL, UK

Full list of author information is available at the end of the article
}

the promising green and sustainable approach to supplement the use of fossil-derived feedstocks, where a carbon reservoir present in the biomass is exploited for the integrated production of chemicals, fuels and energy. First generation biorefineries that use edible biomass feedstocks are well established. The food versus fuel debate gave rise to second generation biorefineries based on non-edible feedstocks and biomass wastes $[2,3]$. These feedstocks have drawn significant attention as they can generate high value products from a renewable carbon

c) The Author(s) 2020. This article is licensed under a Creative Commons Attribution 4.0 International License, which permits use, sharing, adaptation, distribution and reproduction in any medium or format, as long as you give appropriate credit to the original author(s) and the source, provide a link to the Creative Commons licence, and indicate if changes were made. The images or other third party material in this article are included in the article's Creative Commons licence, unless indicated otherwise in a credit line to the material. If material is not included in the article's Creative Commons licence and your intended use is not permitted by statutory regulation or exceeds the permitted use, you will need to obtain permission directly from the copyright holder. To view a copy of this licence, visit http://creativeco mmons.org/licenses/by/4.0/. The Creative Commons Public Domain Dedication waiver (http://creativecommons.org/publicdomain/ zero/1.0/) applies to the data made available in this article, unless otherwise stated in a credit line to the data. 
source. Over the last two decades, there has been a large amount of research dedicated to the development of bioprocesses based on agro-industrial wastes [4].

Lignocellulosic biomass (LCB) is the most abundant biomass on earth and has three major components namely cellulose (34-50\%), hemicellulose (19-34\%) and lignin (11-30\%). Hemicellulose, a hetero-polysaccharide consists largely of xylose $(\sim 90 \%)$, which contributes to $15-35 \%$ of the total dry cell weight of LCB [5, 6]. Despite being the second most abundant sugar after glucose, xylose valorisation through biotechnological routes is often overlooked. Most of the microbeslack xylose assimilation pathways as xylose is rarely present in the environment and in free form in natural products. If the pathways exist, it is not a preferred carbon source and its uptake is suppressed in the presence of glucose due to carbon catabolite repression [7]. These challenges make pentose sugar a lesser lucrative option as an exploitable carbon source. However, efficient utilisation of xylose is essential for the commercial viability of lignocellulosic biorefineries [8, 9]. Like xylose/ LCB, crude glycerol (CG) is another waste product of interest as a carbon source for microbial conversion. CG is major by-product of many industrial processes, such as bioethanol, oleochemical, chemical and biodiesel. The rapid growth in the biodiesel industry has led to an increase in CG production [10] with $\sim 10 \mathrm{~kg}$ of CG production for every $100 \mathrm{~kg}$ of biodiesel. Biodiesel production increased exponentially from 2005 to 2015 and is forecasted to grow by another $35 \%$ by 2025 [11]. The surplus of biomass derived by-product streams like xylose and CG has emphasised the need to utilise them as carbon sources and avoid their disposal. It is therefore necessary to develop sustainable processes to transform these streams into promising value-added products.

Xylitol is a commercially important chemical. According to the US Department of Energy, xylitol is one of the top twelve platform chemicals, which can be produced from biomass [12]. Chemically, it is a polyol (sugar alcohol) containing five carbon atoms where a hydroxyl group is attached to each carbon atom. Xylitol is produced chemically/biochemically by the reduction of xylose. The molecule is equivalent to sucrose in sweetness but has less calories and lower glycaemic index [5, 13]. Due to its high endothermicity, low glycaemic rates, cariostatic properties, lack of carcinogenicity, non-involvement in the insulin metabolic pathway and non-interference with food nutritional value, xylitol has many applications in the food and pharmaceutical industries [14]. Xylitol has a large market and a $12 \%$ share of the total polyols market, which is expanding rapidly. The global market for xylitol in 2016 was 190,900 metric tons and is anticipated to reach 266,500 metric tons in 2022 with a value greater than US\$ 1 billion [6].

Yarrowia lipolytica is a non-conventional, oleaginous, safe and robust yeast with multiple biotechnological applications. It has versatile characteristics such as high cell density cultivation, metabolic flexibility and tends to accumulate a wide array of industrially important metabolites. In addition, the yeast is non-pathogenic and has a GRAS (generally regarded as safe) status [15]. The unique features of $Y$. lipolytica make it a promising cell factory for the production of value-added chemicals. Glycerol is the most preferred carbon source for Y. lipolytica and can metabolize it with great efficiency [16-18]. According to the literature, the majority of the Yarrowia strain cannot grow on xylose as they possess strong xylose reductase activity but have low xylitol dehydrogenase activity, however, some can biotransform xylose into xylitol $[19,20]$.

The current study was undertaken to investigate the xylitol accumulating ability of $Y$. lipolytica Po1t $\left(\mathrm{Ura}^{+}\right.$, $\mathrm{Leu}^{+}$) [19]. The biotransformation of xylose into xylitol was carried out by growing Y. lipolytica on pure glycerol (PG), CG as well as glucose The work studies the screening of co-substrates for cell growth, media optimization in a shake flask, scale up in bioreactor and downstream processing of xylitol. This study is the first to demonstrate the potential of using Y. lipolytica as a microbial cell factory for xylitol synthesis from inexpensive feedstocks.

\section{Results \\ Shake flask screening of co-substrates for growth of Yarrowia lipolytica and subsequent biotransformation of xylose to xylitol}

The biotransformation of xylose to xylitol using Y. lipolytica cell factory was evaluated under shake flask conditions. The Y. lipolytica Polt $\left(\mathrm{Ura}^{+} \mathrm{Leu}^{+}\right)$strain used in this study can transform xylose into xylitol but it cannot grow on xylose as a sole carbon source (data not shown). Two carbon sources namely glucose and glycerol were evaluated for biomass accumulation of $Y$. lipolytica cells and subsequent biotransformation of xylose into xylitol. The growth profile of $Y$. lipolytica clearly indicated that the assimilation of glycerol was faster than that of glucose as shown by Fig. 1 . The yeast was able to consume $20.0 \mathrm{~g} / \mathrm{L}$ of glycerol within $48 \mathrm{~h}$ whereas more than $15 \%$ of glucose was left unconsumed in the same time and complete glucose consumption was evident by $72 \mathrm{~h}$. The highest $\mathrm{OD}_{600}$ values obtained for glycerol and glucose were quite similar, 29.2 and 28.0, respectively. After the majority of glucose or glycerol was exhausted $(\sim 48 \mathrm{~h})$, biotransformation began and in the next $24-48 \mathrm{~h}$, the maximum production of xylitol was recorded. However, owing to earlier consumption of glycerol than glucose, the biotransformation rate was significantly faster in 
the former case than the later and the maximum xylitol production was achieved in $72 \mathrm{~h}$ for glycerol compared to $96 \mathrm{~h}$ for glucose. Using glycerol as a co-substrate, the xylitol titre was $16.0 \mathrm{~g} / \mathrm{L}$ with a yield of $0.80 \mathrm{~g} / \mathrm{g}$, however, when glucose was used as a co-substrate the highest xylitol titer and conversion yield were $12.7 \mathrm{~g} / \mathrm{L}$ and $0.64 \mathrm{~g} / \mathrm{g}$, respectively. The $\mathrm{pH}$ decreased during the growth phase, reducing below 4.0 after $48 \mathrm{~h}$ and then remained almost constant during the xylitol production phase. The biotransformation yield obtained was higher with glycerol and was therefore selected as the co-substrate for further experiments.

\section{Media optimization in shake flask to maximize biotransformation of xylose to xylitol Central composite design (CCD)}

Statistical methods measure the effects of changing operating variables and their mutual interactions on the process through experimental design techniques. In the present study, the central composite design (CCD) was employed to determine the optimum value of media components (xylose, $\mathrm{YNB}, \mathrm{NH}_{4} \mathrm{Cl}$ and phosphate buffer) to maximize xylitol production in shake flask while keeping glycerol concentration constant. The design matrix and the corresponding results of observed and predicted responses (xylitol titre) are shown in Table 1. The experimental run 8 resulted in the production of $37.2 \mathrm{~g} / \mathrm{L}$ xylitol for a $50.0 \mathrm{~g} / \mathrm{L}$ initial concentration of xylose (Table 1). However, the best run in terms of xylitol yield was found for run 9 where $0.95 \mathrm{~g}_{\text {xylitol }} / \mathrm{g}_{\text {xylose }}$ was produced for an initial xylose concentration of $20.0 \mathrm{~g} / \mathrm{L}$.

The results were analysed using the Analysis of Variance (ANOVA) shown in Table 2. The error term, which indicates that the amount of variation in the response data, is very low. According to the ANOVA, the regression model for the xylitol production showed high significance with a Fisher's F value of 22.41 and explains most of the variations present in the experimental design [21]. The "p" value of 0.92 for lack of fit indicated that the response for xylitol concentration was not significant relative to the pure error. The correlation coefficient $\left(R^{2}\right)$ between the experimental and model-predicted values of response variables showed high statistical significance of $94.16 \%$, which implies that only $5.84 \%$ of the total variation was not explained by the model. The Student's $t$ distribution and the corresponding $\mathrm{p}$ values shows that most of the interaction terms are statistically significant $(\mathrm{P}<0.05)$, except for the interaction terms involving xylose with $\mathrm{NH}_{4} \mathrm{Cl}$ and phosphate buffer which showed insignificance. The second-order polynomial equation for xylitol production by $\mathrm{CCD}$ is given in Eq. (1).

$$
\begin{aligned}
\mathrm{Y}_{\text {xylitol }}= & 25.90+4.45 \mathrm{X}_{1}+1.46 \mathrm{X}_{2}-0.75 \mathrm{X}_{3} \\
& -0.68 \mathrm{X}_{4}+0.008 \mathrm{X}_{1}^{2}-3.64 \mathrm{X}_{2}^{2}+0.27 \mathrm{X}_{3}^{2} \\
& -1.35 \mathrm{X}_{4}^{2}+0.36 \mathrm{X}_{1} \mathrm{X}_{2}+1.42 \mathrm{X}_{1} \mathrm{X}_{3} \\
& -0.33 \mathrm{X}_{1} \mathrm{X}_{4}+3.7 \mathrm{X}_{2} \mathrm{X}_{3}-0.15 \mathrm{X}_{2} \mathrm{X}_{4} \\
& -2.8 \mathrm{X}_{3} \mathrm{X}_{4}
\end{aligned}
$$

where $\mathrm{Y}$ is the xylitol concentration $(\mathrm{g} / \mathrm{L})$ and $\mathrm{X}_{1}, \mathrm{X}_{2}, \mathrm{X}_{3}$ and $\mathrm{X}_{4}$ are xylose $(\mathrm{g} / \mathrm{L}), \mathrm{YNB}(\mathrm{w} / \mathrm{v} \%)$, ammonium chloride (w/v \%) and phosphate buffer $(\mathrm{mM})$, respectively.

The response surface plot for the interaction between the media components is shown in Fig. 2. The 3D surface plot gives an overview of the interaction between the two components on xylitol production by keeping the other parameters at central values. The interaction between xylose and $\mathrm{NH}_{4} \mathrm{Cl}$ showed a positive effect on xylitol production and a progressive increment in the xylitol titer was observed with the increasing concentration of both components. Further, higher xylose concentrations caused a steep reduction in xylitol titer. Similarly, the interactions between xylose \& YNB (Fig. 2b) and $\mathrm{NH}_{4} \mathrm{Cl}$ \& YNB (Fig. 2d) showed positive effects $(\mathrm{P}<0.05)$ on xylitol production indicating that higher concentrations of $\mathrm{YNB}$ and $\mathrm{NH}_{4} \mathrm{Cl}$ will lead to the enhanced production of xylitol. On the other hand, the interaction between xylose \& phosphate buffer (Fig. 2c), phosphate buffer \& $\mathrm{NH}_{4} \mathrm{Cl}$ (Fig. 2e) and YNB \& phosphate buffer (Fig. 2f) showed statistical insignificant values, which indicate one of the components has to be kept at a minimum to enhance the xylitol production.

\section{Optimization of process parameters using artificial neural network linked genetic algorithm (ANN-GA)}

The experimental design generated by the CCD was used as input feed for ANN algorithm. The overall data set were divided into three subsets: training (20 data points), validation ( 5 data points) and test sets ( 5 data points). The training was carried for 1000 epochs, the mean square error (MSE) and $R^{2}$ value for data set involved in xylitol production are shown in Additional file 1: Table S1. The data points apart from the training are used to examine the validation. During training the data over fits and substantial error will be accumulated on the validation. When the error on the validation reaches the threshold point the weights and biases are adjusted to minimize the error $[22,23]$. Network topology have a crucial role in predicting results, the input-output neuron of ANN is the resemblance of input and output data used in this study. The number of neurons in the hidden layer was determined by trial and error method to minimize MSE. The MSE of xylitol production was found to be 7.425. The 

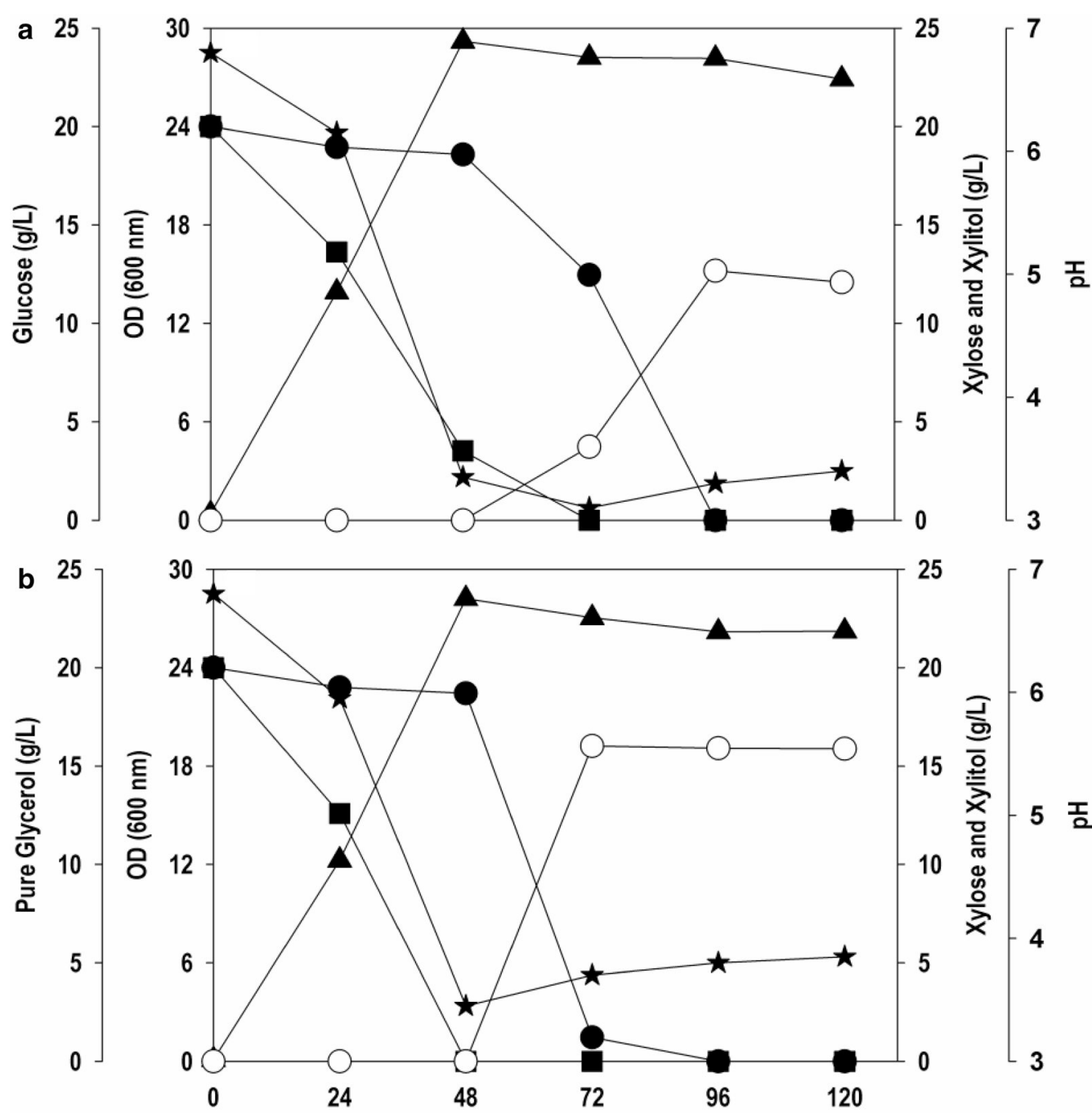

Time (h)

Fig. 1 Time course profiles of Y. lipolytica on; a glucose and xylose, b PG and xylose. Symbols: filled square (glucose or PG), filled circle (xylose), filled triangle $\left(\mathrm{OD}_{600}\right)$, empty circle (xylitol) and filled star $(\mathrm{pH})$

predicted value of ANN for xylitol is shown in Table 1. The optimum value was achieved with 4 inputs, 8 hidden layers and 1 output layer. The simulation of ANN resulted in a $R^{2}$ of 0.938 between the actual experimental production values (Fig. 3a). In order to further optimize the solution space for global optimum, the genetic algorithm (GA) was adapted to train ANN values. The values of GA specific parameters used in the optimization technique were as follows: population size $=20$, cross over probability $=0.8$, mutation probability $=0.01$, No. of generation $=100$. The maximum xylitol production of $47.7 \mathrm{~g} / \mathrm{L}$ was observed with 160 iterations. The best fitness plot of the GA for xylitol production (Fig. 3b) maps the gradual convergence of the best fitness values of successive generations towards the final optimum value. The optimum values were found to be as following: xylose-55.0 g/L, $\mathrm{NH}_{4} \mathrm{Cl}-3.94 \mathrm{~g} / \mathrm{L}, \mathrm{YNB}-5.0 \mathrm{~g} / \mathrm{L}$ and phosphate buffer-132.5 mM.

\section{Model validation under shake flask conditions}

The validation experiments were performed in shake flasks based on the global optimum values obtained by ANN-GA training. Three different sets of experiments were conducted: PG+xylose (Fig. 4a); CG+xylose (Fig. 4b); PG + crude xylose (Fig. 4c). The crude carbon sources were included to test the ability of the $Y$. lipolytica strain to tolerate, utilize and valorise crude renewable sources. The glycerol uptake rate was similar for the case of PG and CG and the major fraction of glycerol carbon was depleted in first $48 \mathrm{~h}$. The cell concentration 
Table 1 CCD and ANN design matrix of variables with experimental and predicted response for xylitol production

\begin{tabular}{|c|c|c|c|c|c|c|c|}
\hline $\begin{array}{l}\text { Experiment } \\
\text { no. }\end{array}$ & Xylose (g/L) & $\mathrm{NH}_{4} \mathrm{Cl}(\mathrm{w} / \mathrm{v} \%)$ & YNB (w/v \%) & $\begin{array}{l}\text { Phosphate } \\
\text { buffer (mM) }\end{array}$ & Xylitol (g/L) & CCD predicted & ANN predicted \\
\hline 1 & 20 & 0.2 & 0.2 & 35 & 17.47 & 18.04 & 18.79 \\
\hline 2 & 50 & 0.2 & 0.2 & 35 & 22.20 & 22.80 & 22.48 \\
\hline 3 & 20 & 0.5 & 0.2 & 35 & 13.11 & 11.81 & 14.99 \\
\hline 4 & 50 & 0.5 & 0.2 & 35 & 20.05 & 19.51 & 20.45 \\
\hline 5 & 20 & 0.2 & 0.5 & 35 & 10.20 & 10.52 & 4.83 \\
\hline 6 & 50 & 0.2 & 0.5 & 35 & 21.77 & 22.48 & 19.70 \\
\hline 7 & 20 & 0.5 & 0.5 & 35 & 18.70 & 20.81 & 18.92 \\
\hline 8 & 50 & 0.5 & 0.5 & 35 & 37.22 & 35.73 & 33.50 \\
\hline 9 & 20 & 0.2 & 0.2 & 100 & 18.99 & 26.02 & 23.06 \\
\hline 10 & 50 & 0.2 & 0.2 & 100 & 29.53 & 27.94 & 30.42 \\
\hline 11 & 20 & 0.5 & 0.2 & 100 & 17.85 & 17.65 & 19.66 \\
\hline 12 & 50 & 0.5 & 0.2 & 100 & 23.30 & 22.52 & 23.14 \\
\hline 13 & 20 & 0.2 & 0.5 & 100 & 4.74 & 5.79 & 5.90 \\
\hline 14 & 50 & 0.2 & 0.5 & 100 & 14.07 & 14.91 & 13.92 \\
\hline 15 & 20 & 0.5 & 0.5 & 100 & 15.00 & 13.95 & 14.27 \\
\hline 16 & 50 & 0.5 & 0.5 & 100 & 26.08 & 26.03 & 31.47 \\
\hline 17 & 35 & 0.35 & 0.35 & 67.5 & 20.71 & 24.25 & 24.96 \\
\hline 18 & 35 & 0.35 & 0.35 & 67.5 & 27.18 & 24.25 & 24.96 \\
\hline 19 & 35 & 0.35 & 0.35 & 67.5 & 24.53 & 24.25 & 24.96 \\
\hline 20 & 35 & 0.35 & 0.35 & 67.5 & 24.84 & 24.25 & 24.96 \\
\hline 21 & 5 & 0.35 & 0.35 & 67.5 & 20.57 & 19.33 & 21.37 \\
\hline 22 & 65 & 0.35 & 0.35 & 67.5 & 34.98 & 36.16 & 37.22 \\
\hline 23 & 35 & 0.05 & 0.35 & 67.5 & 12.41 & 10.67 & 11.56 \\
\hline 24 & 35 & 0.65 & 0.35 & 67.5 & 13.88 & 15.55 & 15.66 \\
\hline 25 & 35 & 0.35 & 0.05 & 67.5 & 29.69 & 30.82 & 29.96 \\
\hline 26 & 35 & 0.35 & 0.65 & 67.5 & 28.00 & 26.80 & 23.25 \\
\hline 27 & 35 & 0.35 & 0.35 & 2.5 & 23.62 & 23.15 & 23.75 \\
\hline 28 & 35 & 0.35 & 0.35 & 132.5 & 21.03 & 21.43 & 21.08 \\
\hline 29 & 35 & 0.35 & 0.35 & 67.5 & 24.87 & 27.46 & 24.96 \\
\hline 30 & 35 & 0.35 & 0.35 & 67.5 & 29.78 & 27.46 & 24.96 \\
\hline
\end{tabular}

obtained with PG $\left(\mathrm{OD}_{600}\right.$ : 34.2) was higher than CG $\left(\mathrm{OD}_{600}: 24.9\right)$. The low cell $\mathrm{OD}_{600}$ in comparison to PG might be attributed due to the presence of some inhibitory components such as methanol present in the CG [24]. The results showed significant improvements in xylitol titer and yield in comparison to unoptimized composition. For the case of PG and xylose, 98\% of xylose was transformed into xylitol, and a xylitol concentration of $54.0 \mathrm{~g} / \mathrm{L}$ was achieved. On the other hand, for the cofermentation of CG and xylose, a xylitol titre of $48.2 \mathrm{~g} / \mathrm{L}$ was obtained with a conversion yield of $0.88 \mathrm{~g} / \mathrm{g}$. This difference could be attributed to the composition of CG. The higher buffer concentration of optimized medium suppressed the reduction in $\mathrm{pH}$, and therefore, after an initial drop, the $\mathrm{pH}$ was stable around 5.5. The $\mathrm{pH}$ plays a crucial role in the transportation of xylose across the membrane [25].
The ability of $Y$. lipolytica to produce xylitol from crude xylose was also tested. For this, crude xylose obtained after hydrothermal pretreatment of sugarcane bagasse was used. Lignocellulosic material often contains compounds such as phenols, furan derivatives and aliphatic acids in large amounts which tend to inhibit microbial growth [26]. However, the cell growth $\left(\mathrm{OD}_{600}: 29.1\right)$ was faster and almost unaffected by the presence of impurities/inhibitory molecules in crude xylose. The higher cell growth could also be contributed by other sugars such as glucose in the sugarcane bagasse (SCB) hydrolysate [27]. The conversion of crude xylose was $54 \%$ with the xylitol titre of $5.4 \mathrm{~g} / \mathrm{L}$. The low conversion yields obtained indicating the effect of impurities on the biotransformation ability of Y. lipolytica. A plausible reason for the low biotransformation yield from the xylose-rich SCB hydrolysate when compared to pure xylose could be due to its 
Table 2 Analysis of variance for xylitol production

\begin{tabular}{|c|c|c|c|c|c|c|}
\hline Source & DF & Seq SS & Adj SS & Adj MS & $F$ & $p$ \\
\hline Blocks & 1 & 68.61 & 68.61 & 68.61 & 15.35 & 0.002 \\
\hline Regression & 14 & 1402.25 & 1402.25 & 100.16 & 22.41 & $<0.001$ \\
\hline Linear & 4 & 489.28 & 489.28 & 122.32 & 27.37 & $<0.001$ \\
\hline Xylose & 1 & 424.91 & 424.91 & 424.91 & 95.08 & $<0.001$ \\
\hline $\mathrm{NH}_{4} \mathrm{Cl}$ & 1 & 35.71 & 35.71 & 35.71 & 7.99 & 0.01 \\
\hline YNB & 1 & 24.22 & 24.22 & 24.22 & 5.42 & 0.04 \\
\hline Phosphate & 1 & 4.44 & 4.44 & 4.44 & 0.99 & 0.37 \\
\hline Square & 4 & 404.82 & 404.82 & 101.21 & 22.65 & $<0.001$ \\
\hline Xylose*Xylose & 1 & 9.54 & 0.14 & 0.14 & 0.03 & 0.86 \\
\hline $\mathrm{NH}_{4} \mathrm{Cl}^{*} \mathrm{NH}_{4} \mathrm{Cl}$ & 1 & 341.93 & 352.75 & 352.75 & 78.93 & $<0.001$ \\
\hline YNB*YNB & 1 & 7.65 & 3.14 & 3.14 & 0.7 & 0.42 \\
\hline Phosphate*Phosphate & 1 & 45.7 & 45.7 & 45.70 & 10.23 & 0.01 \\
\hline Interaction & 6 & 508.15 & 508.15 & 84.69 & 18.95 & $<0.001$ \\
\hline Xylose ${ }^{*} \mathrm{NH}_{4} \mathrm{Cl}$ & 1 & 8.73 & 8.73 & 8.73 & 1.95 & 0.18 \\
\hline Xylose*YNB & 1 & 51.99 & 51.99 & 51.99 & 11.63 & 0.004 \\
\hline Xylose*Phosphate & 1 & 8.09 & 8.09 & 8.09 & 1.81 & 0.2 \\
\hline $\mathrm{NH}_{4} \mathrm{Cl}{ }^{*} \mathrm{YNB}$ & 1 & 273.24 & 273.24 & 273.24 & 61.14 & $<0.001$ \\
\hline $\mathrm{NH}_{4} \mathrm{Cl}$ *Phosphate & 1 & 4.56 & 4.56 & 4.56 & 1.02 & 0.33 \\
\hline YNB*Phosphate & 1 & 161.56 & 161.56 & 161.56 & 36.15 & $<0.001$ \\
\hline Residual Error & 14 & 62.57 & 62.57 & 4.47 & & \\
\hline Lack-of-Fit & 10 & 29.03 & 29.03 & 2.90 & 0.35 & 0.92 \\
\hline Pure Error & 4 & 33.54 & 33.54 & 8.38 & & \\
\hline Total & 29 & 1533.43 & & & & \\
\hline
\end{tabular}

DF: degree of freedom; Seq SS: sequential sum of square; Adj SS: adjusted sum of square; Adj MS: adjusted mean square; F: variance ratio (Fisher F-value); p: probability value

direct use without detoxification. Generally hydrothermal pretreatment leads to hydrolysis of acetyl groups attached to the hemicellulosic backbone and as a result acetic acid is formed [28]. It is likely that acetic acid and other furan aldehydes were inhibitory and their presence negatively affected the performance of $Y$. lipolytica during biotransformation. This experiment also gave an insight into the importance of undertaking a detoxification step to remove or minimize the inhibitory compounds.

\section{Submerged batch cultivations in bioreactor}

In order to scale up the fermentation and validate the optimized medium composition, batch cultivations were carried out in a $2.5 \mathrm{~L}$ scale bench bioreactor with $1 \mathrm{~L}$ working volume. The process condition mimicked was exactly that of the shake flask studies except for the aeration. The aeration rate was maintained at $2.0 \mathrm{~L} / \mathrm{min}$ for first $48 \mathrm{~h}$ and then reduced to $1.0 \mathrm{~L} / \mathrm{min}$ for the rest of the test. Two separate batch fermentations were run with PG/xylose and CG/xylose. The time course profiles for both the fermentations were similar to that of the shake flask cultivations. Glycerol is the most preferred carbon source for $Y$. lipolytica and the presence of glycerol repressed the uptake of xylose as evident in
Fig. 5. The gradual uptake of xylose concomitant with xylitol production was noticed when glycerol was almost completely exhausted. The maximum cell $\mathrm{OD}_{600}$ of 48.6 was observed at $120 \mathrm{~h}$ with co-fermentation of PG and xylose, which is higher than achieved during shake flask cultivation. By the end of $168 \mathrm{~h}$ there was complete consumption of xylose and a maximum $53.2 \mathrm{~g} / \mathrm{L}$ xylitol (Fig. 5a) was produced with a yield of $0.97 \mathrm{~g} / \mathrm{g}$. The fermentation profile of $Y$. lipolytica with $\mathrm{CG}$ and pure xylose is shown in Fig. 5b. The maximum cell $\mathrm{OD}_{600}$ recorded was 31.8, not far from the value obtained in the shake flask studies. The yield of the xylitol was about $0.92 \mathrm{~g} / \mathrm{g}$ with a titre of $50.5 \mathrm{~g} / \mathrm{L}$. Furthermore, $\mathrm{pH}$ for the fermentation using pure carbon source fluctuated between 6.5 and 4.7, whereas in the fermentation with CG the pH reduced to 4.3. It is plausible that CG had some impurities which interfered with the buffer capacity of the phosphate buffer, resulting in further drop in $\mathrm{pH}$. In the growth phase $(0-48 \mathrm{~h})$ where biomass accumulation took place, aeration rate was high as glycerol assimilation is known to be dependent on the oxygen uptake rate [29]. Low aeration is maintained in the bioreactor during the xylitol production phase because excess aeration causes re-oxidation of NADH, a co-factor 

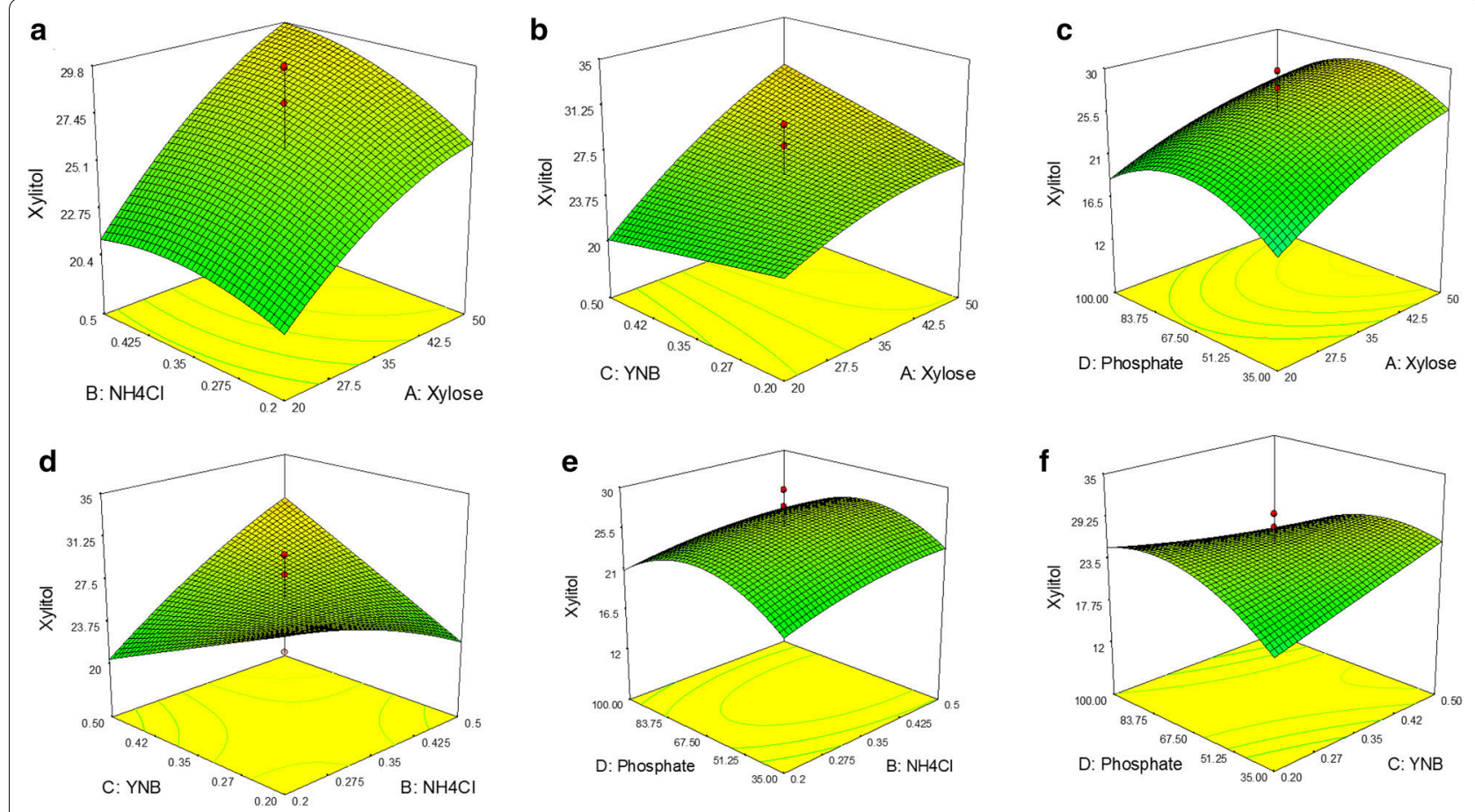

Fig. 2 Three-dimensional response surface plot for xylitol production showing the interactive effects of $\mathbf{a}$ xylose \& $\mathrm{NH}_{4} \mathrm{Cl}, \mathbf{b}$ xylose \& YNB, c xylose \& phosphate buffer, $\mathbf{d}$ YNB \& $\mathrm{NH}_{4} \mathrm{Cl}$, e phosphate buffer \& $\mathrm{NH}_{4} \mathrm{Cl}$ and $\mathbf{f} Y \mathrm{NB}$ \& phosphate buffer
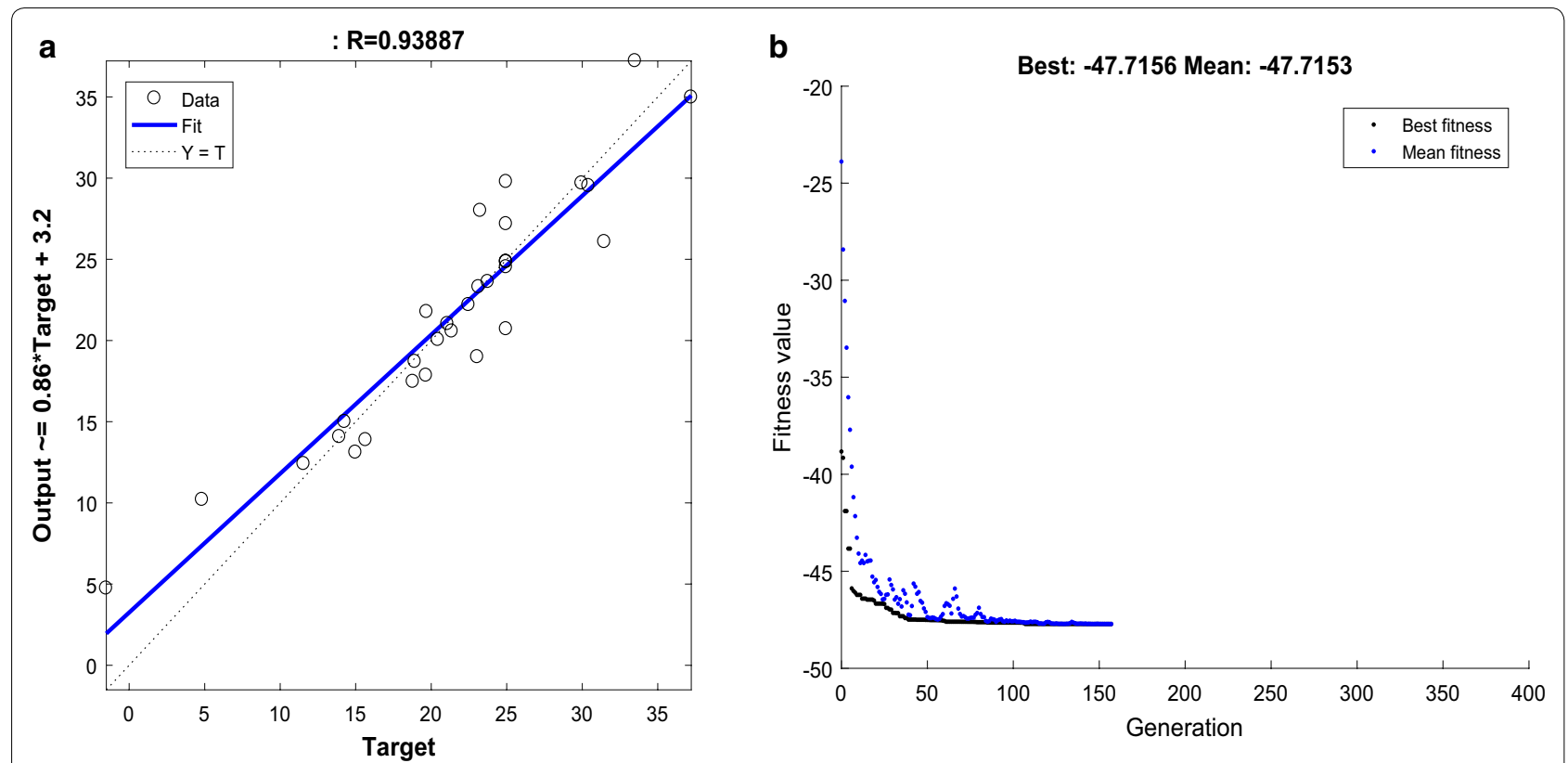

Fig. 3 The prediction performance of ANN models for xylitol production: a overall regression value of simulated ANN; $\mathbf{b}$ best and average fitness values with successive generations showed gradual convergence to the optimum value

necessary for xylitol production from xylose and NAD ${ }^{+}$ produced can facilitate further metabolism of xylitol for cell growth [30].

\section{Xylitol production by resting cells}

Resting cells are metabolically active non-growing cells [31]. Resting cells show an advantage over active cells such as simple operation, no requirement of nutrient 

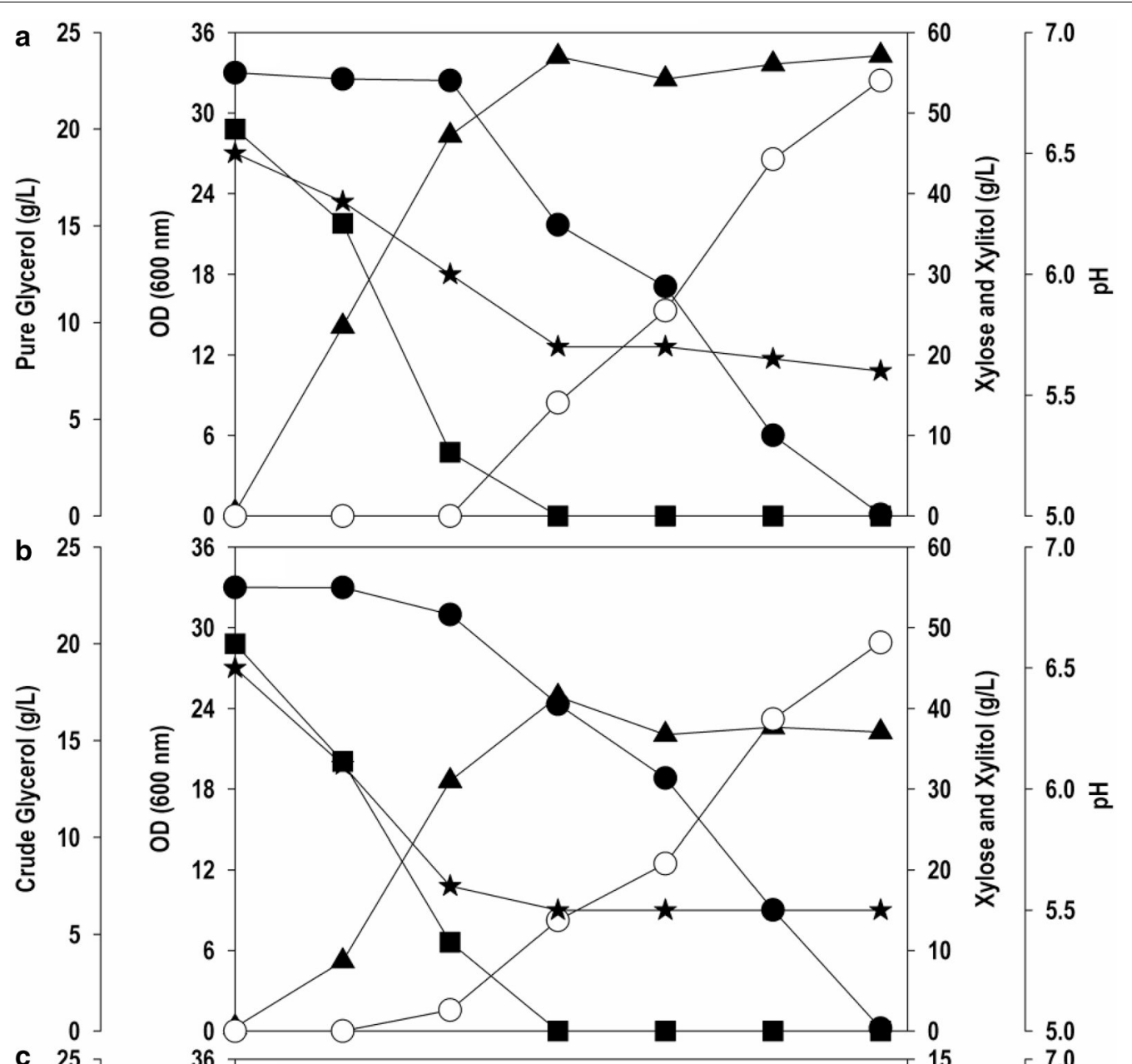

7.0
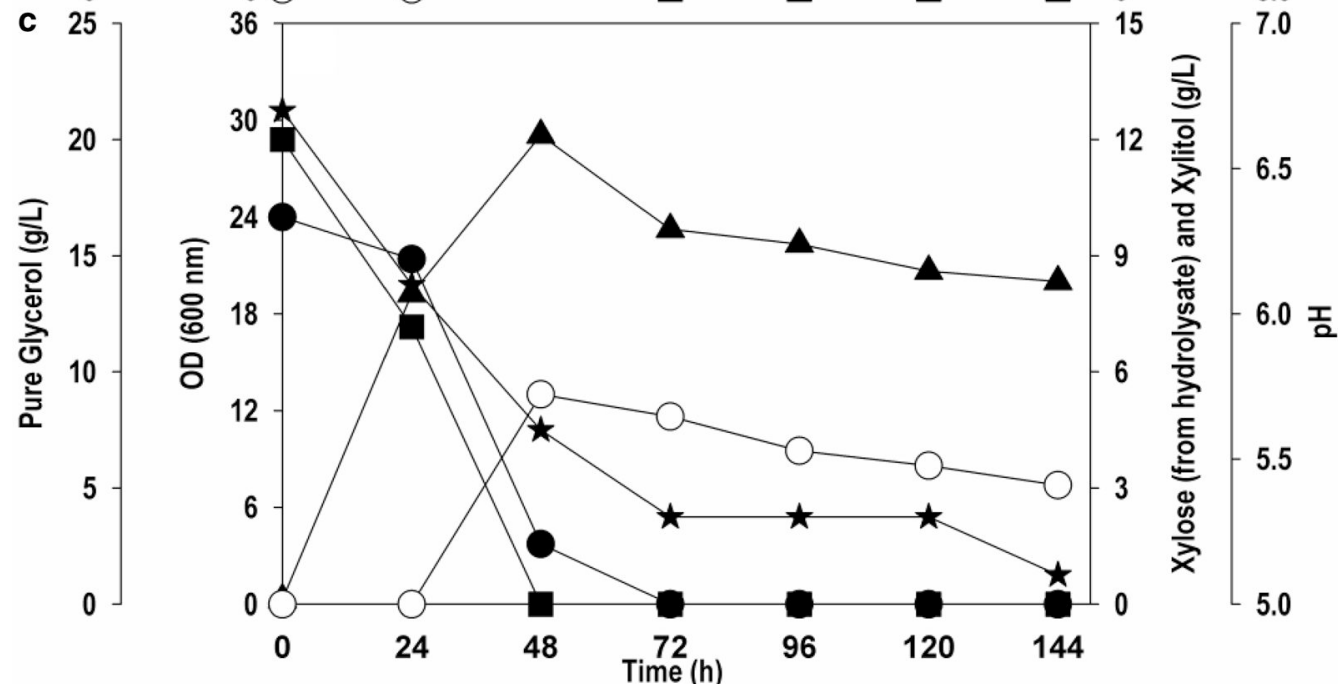

Fig. 4 Shake flask cultivation of Y. lipolytica using optimized media on; a PG and xylose, b CG and xylose, c PG and xylose from SCB hydrolysate. Symbols: filled square ( $\mathrm{PG}$ or $\mathrm{CG})$, filled circle (xylose), filled triangle $\left(\mathrm{OD}_{600}\right)$, empty circle (xylitol) and filled star $(\mathrm{pH})$ 

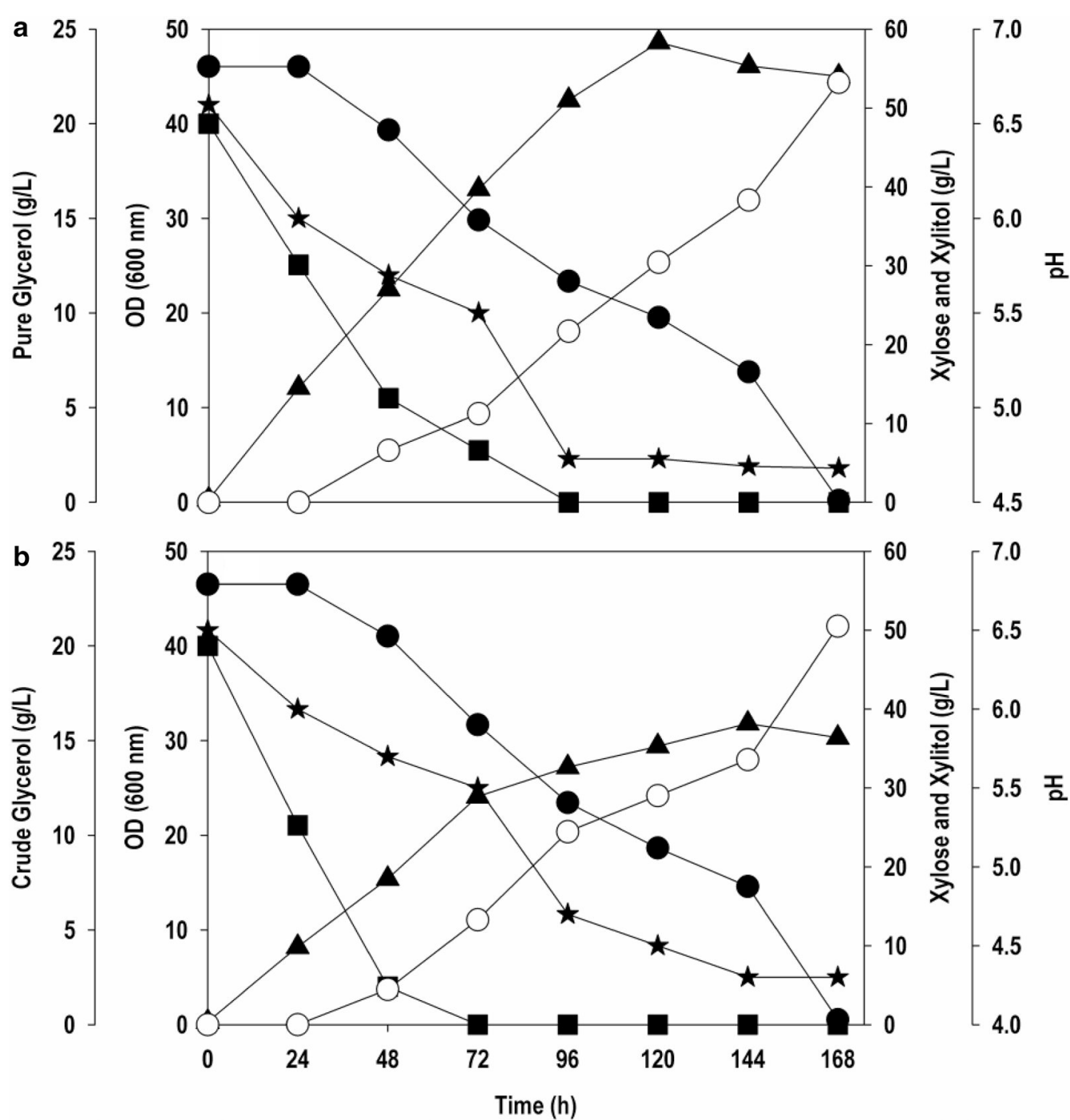

Fig. 5 Batch kinetics of substrate assimilation, cell growth, $\mathrm{pH}$ and xylitol formation by Y. lipolytica in bioreactor during co-fermentation on; a PG and xylose, $\mathbf{b}$ CG and xylose. Symbols: filled square (PG or CG), filled circle (xylose), filled triangle $\left(\mathrm{OD}_{600}\right.$ ), empty circle (xylitol) and filled star ( $\mathrm{pH}$ )

medium and convenient downstream processing [32, 33]. In the current study $Y$. lipolytica is carrying out a single step biotransformation of xylose to xylitol. It is therefore worth exploring the potential of the yeast as a biocatalyst for the continuous production of xylitol through reusability of the cells; in other words, the growth phase was split from the xylitol production phase. The Y. lipolytica cells were grown using the PG and CG in shake flask using the culture medium as described in "Material and methods" section. The fermentation was terminated once the cell $\mathrm{OD}_{600}$ reached 20-25, nearly after $48 \mathrm{~h}$ and the cells were collected through centrifugation. The obtained cell pellet was suspended in buffer containing only xylose. The feasibility of using the resting cells of Yarrowia lipolytica for xylose biotransformation was checked by suspending the glycerol grown cell pellets in buffer containing three different concentrations of xylose $(30,70$ and $100 \mathrm{~g} / \mathrm{L})$. It is evident from Fig. 6 that the conversion of xylose to xylitol was not satisfactory. The xylitol obtained for the case of cells accumulated on CG was $\sim 10 \mathrm{~g} / \mathrm{L}$ regardless of xylose concentration. The performance of the resting cells grown in PG were better and the highest amount of xylitol recorded with PG grown cell was $\sim 28 \mathrm{~g} / \mathrm{L}$ from $30 \mathrm{~g} / \mathrm{L}$ xylose. The experimental results clearly indicated that the xylitol biotransformation yield significantly reduced with further increase in xylose levels. The probable cause for the cessation of the biocatalytic activity, may be due to the lack of ability of the already built biomass of Y. lipolytica cells to replenish the rate limiting cofactors for continuous and smooth biotransformation as 


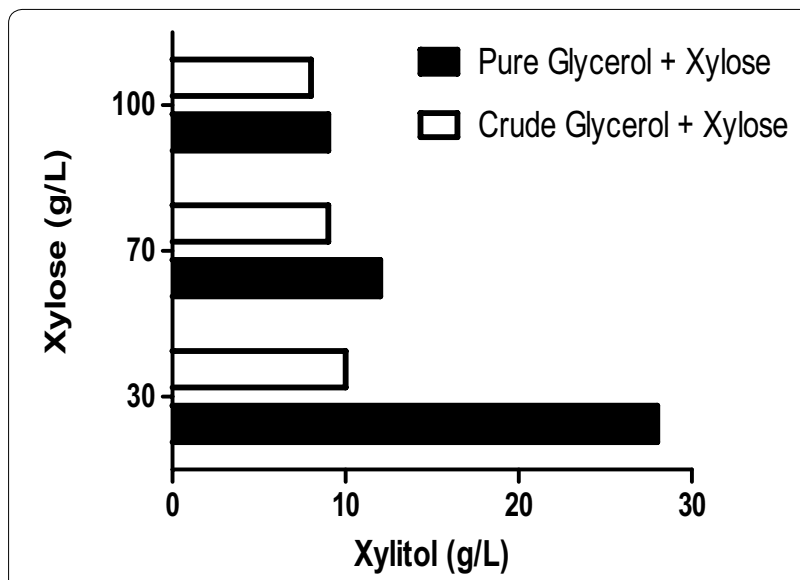

Fig. 6 Biotransformation of xylose to xylitol by resting cells of $Y$. lipolytica grown using PG and CG

there was no nutrient in the bioconversion stage to support cofactor supply. The presence of xylose alone in the media would not be sufficient to produce the cofactors required for the conversion.

\section{Purification of xylitol from the fermentation broth}

Downstream processing costs are usually one of the major obstacles for the economical production of chemicals. Crystallization is the more commonly adopted method in the purification of polyols as it allows recovery of xylitol in a purified form in a single step. In terms of energy consumption, crystallization is less energy intensive when compared to a distillation process. Crystallization can be performed using various methods such as solvent evaporation, cooling and salting out [34]. Xylitol is a solid at room temperature with melting point $>90^{\circ} \mathrm{C}$. In the initial step, the coloured substance recovered was clarified using charcoal treatment, with $5 \%$ activated charcoal. The fermentation broth almost became translucent and the impurities such as residual xylose were removed. The recovery of xylitol after charcoal treatment step was 76.2 and $77.1 \%$ for CG/xylose and PG/xylose, respectively, as shown in Table 3 . A subsequent alcohol precipitation step further reduced the recovery of xylitol. The final crystallization step carried out at $-20{ }^{\circ} \mathrm{C}$ for $72 \mathrm{~h}$ resulted in 35.3 and $39.5 \%$ xylitol recovery for CG/ xylose and PG/xylose, respectively (Table 3 ). Despite the presence of impurities, similar recovery results were obtained with CG and PG. The results of xylitol recovery are encouraging and can be improved with further modifications.

\section{Discussion}

Xylitol is a polyol of commercial interest due to its high sweetening power and anticariogenic properties. Due to its multiple benefits, the market is growing with an increase of $6 \%$ per year. The industrial route requires pure xylose and the process is operated at high temperature and pressure. The chemical route is advantageous in terms of yield but has a number of hurdles to be overcome such as extensive purification, product recovery, catalyst deactivation, and energy intensity. All these factors make the process expensive and non-sustainable [14]. The biotechnological production of xylitol is environmentally safe and does not use toxic catalysts. The approach would be sustainable and create economic benefits if integrated with waste feedstocks rich in renewable carbon $[13,35]$. The review of the literature shows that there has been two strategies for the bioproduction of xylitol; use of xylose as sole carbon source for cell growth as well as xylitol accumulation; and co-feeding another carbon source along with xylose for biomass formation. The co-fermentation of xylose and another substrate is preferred over the sole use of xylose for microbial xylitol production [36-38]. In the former approach, low yield and productivities are obtained due to a number of reasons; slow metabolism on xylose, partitioning of xylose flux between cell growth and xylitol formation, and reconsumption of produced xylitol. Therefore, it is more desirable to grow cell biocatalysts on a preferred carbon source so that a high cell density could be generated in a short time leading to higher productivities and yield.

The current study examined the potential of non-conventional yeast $Y$. lipolytica for xylitol production which

Table 3 Xylitol titer and percent recovery obtained during different steps of downstream processing of fermentation broth from batch cultivation of $Y$. lipolytica in shake flask on CG/xylose and pure PG/xylose

\begin{tabular}{lllll}
\hline Purification steps & \multicolumn{2}{c}{ CG + Xylose } & & PG + Xylose \\
\cline { 2 - 3 } & Xylitol (g/L) & Recovery (\%) & Xylitol (g/L) & Recovery (\%) \\
\hline Crude fermentation broth & 48.2 & 100 & 54.0 & 100 \\
Activated charcoal treatment & 37.1 & 76.9 & 39.7 & 73.5 \\
Alcohol precipitation & 24.2 & 39.7 & 27.1 & 52.6 \\
Crystallization & 17.2 & 20.3 & 39.5 \\
\hline
\end{tabular}


is known to accumulate high levels of lipids, organic acids and polyols [15]. The biochemical production of xylitol takes place through reduction of xylose to xylitol mediated by xylose reductase (XR) and the electron transfer for this reaction is facilitated through participation of the redox cofactor $\mathrm{NAD}(\mathrm{P}) \mathrm{H}$ (Fig. 7). The produced xylitol is further oxidized to xylulose catalysed by xylitol dehydrogenase $(\mathrm{XDH})$, which is then phosphorylated to xylulose5 -phosphate by enzyme xylulose kinase (XKS) and enters the central carbon metabolism for cell maintenance and growth. The absence of XDH enzyme, its weak activity and/or imbalance in activities of XR/XDH result in accumulation of xylitol $[14,37,39]$. The majority of $Y$. lipolytica strains cannot grow on xylose as documented by many literature reports $[17,19,27]$. According to Rodriguez et al. [20], the complete xylose pathway exists in $Y$. lipolytica but inability to grow robustly on xylose arises due to poor expression of key enzymes (XDH and XKS) controlling the pathway. The $Y$. lipolytica Polt $\left(\mathrm{Ura}^{+}\right.$ $\mathrm{Leu}^{+}$) strain used in the current study and in a previous work [19], has been shown to accumulate xylitol when cultured on xylose. The high yield obtained was a stimulus to carry out a detailed study to investigate the potential of Y. lipolytica for xylitol production.

Xylitol is an extracellular metabolite and its production is affected by many factors including medium composition, cell density and growth rate. Besides high xylose concentrations, an optimal balance of other nutrients is necessary to achieve industrial levels of xylitol [39, 40]. We started growing Y. lipolytica on a mixture of glucose or glycerol and xylose to choose better co-substrate. We obtained similar results for cell growth on both the carbon sources, however, glycerol assimilation was faster than that of glucose. In addition, the biotransformation rate and yield on glycerol were significantly higher than glucose (Fig. 1). Glycerol being a more reduced carbon source than traditional carbohydrates (glucose/sucrose/ xylose) can provide better supply of reducing equivalents $(\mathrm{NAD}(\mathrm{P}) \mathrm{H}$ which is beneficial for xylitol formation [37, 41]. The preference of Y. lipolytica for glycerol is also well documented in literature. The yeast prefers glycerol over glucose and presence of glycerol but not that of glucose represses the uptake of other carbon sources including glucose in co-fermentations [16-18]. Workman et al. [16] found that glycerol assimilation was accompanied with higher oxygen uptake rates in comparison to glucose and maximum growth rate of $Y$. lipolytica on glycerol $\left(0.30 \mathrm{~h}^{-1}\right)$ was $25 \%$ higher than on glucose $\left(0.24 \mathrm{~h}^{-1}\right)$. The hypothesis for glycerol preference/repression like effects by Y. lipolytica is that its genome contain only one hexose transporter but three genes linked with glycerol transport. Lubuta et al. [18] performed RNA-Seq-based transcriptome analysis in $Y$. lipolytica and argued that the higher expression of several transporters could be potentially related to the phenotypic observation of glycerol preference. A similar kind of phenomenon can be envisaged in the present strain as well. In addition, being an oleaginous yeast, $Y$. lipolytica, can consume even the CG, a major industrial by-product with same the efficiency as PG [42].

The media optimization using CCD coupled with ANN-GA resulted in higher biotransformation efficiency, attaining a yield of more than $90 \%$ using PG and CG with xylose. Previously Pappu and Gummadi [43] adapted the ANN-GA model for optimizing process parameters such as $\mathrm{pH}$, temperature and volumetric oxygen transfer co efficient $K_{L a}$ to enhance xylitol production in Debaryomyces nepalensis. With hybrid ANN-GA optimization, they reported an optimum predicted error of $3.5 \%$ and maximized xylitol yield of $0.53 \mathrm{~g} / \mathrm{g}$ in batch bioreactor. The results highlight the importance of nonlinear modelling to optimize parameters in biochemical systems. In our study, nitrogen source $\left(\mathrm{NH}_{4} \mathrm{Cl}\right)$ and YNB showed a momentous effect on the xylitol bioconversion. $\mathrm{NH}_{4} \mathrm{Cl}$ plays a crucial role in enhancing the protein/enzyme expression level as the transcription of carbon metabolising gene is relied upon as the nitrogen source [44]. On the other hand, YNB comprises of essential components such as amino acids, vitamins, salts and trace elements required for yeast growth. Xia et al. [45], reported excellent fermentation capability of xylose by $C$. shehatae in medium supplemented with YNB, whereas impaired growth was witnessed when the medium was devoid of YNB supplementation. In a recent work, YNB was found to be a significant component for xylitol production by Candida tropicalis JA2, when Plackett-Burman design

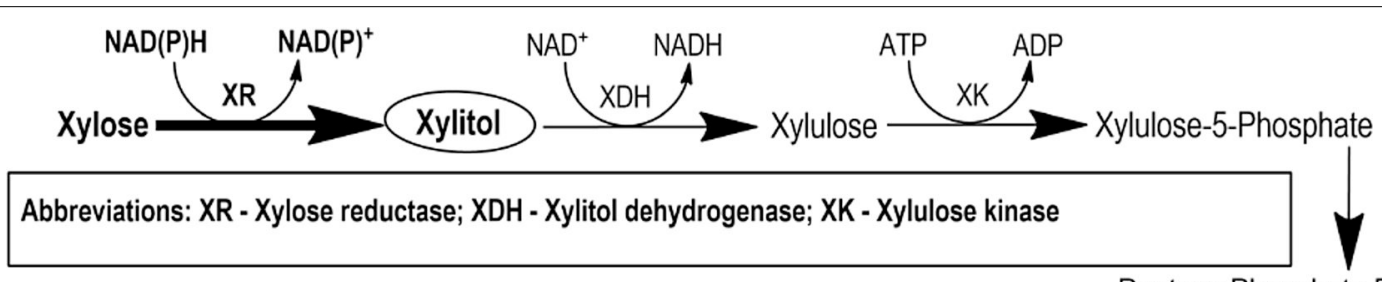

Pentose Phosphate Pathway

Fig. 7 Xylose metabolism in yeast $[5,37]$ 
was done for nitrogen sources and various salts [46]. The results of the shake flask were replicated when the experiments were scaled up in bioreactor. The fermentation profiles can be divided into two phases; growth and biotransformation phase. The biotransformation of xylose started only after when a large fraction of cosubstrate was consumed and may be due to carbon catabolite repression. The interesting observation was that cell growth was continuously increasing even after complete consumption of glycerol as probably, some of the accumulated xylitol was contributing to cell growth after exhaustion of glycerol. More work is required to decode this, however, results are in agreement with those of Ledesma-Amaro et al. [19]. The idea of the resting cell experiment was to investigate the reusability of the cell biocatalysts repeatedly, which will improve the bioprocess economics. Somehow, the results were not very encouraging. We suspect that it could be due to disrupted supply of reduced pyridine nucleotides and in future studies the biotransformation medium could be supplemented with co-substrate at regular interval for uninterrupted supply of a redox cofactor to carry out the reduction reaction [14].

The final step of recovery and purification of a product in a bioprocess is challenging and determines the feasibility of the process, especially for products synthesized from crude renewable sources. Its complexity depends on the nature of product and composition of the fermentation broth. The information on xylitol recovery from fermentation broths is scarce in literature [13]. This study reaffirmed that a low cost easily available adsorbent like activated charcoal could efficiently remove the impurities and simultaneously decolorized the xylitol rich fermentation broth as reviewed previously [34]. Earlier, Gurgel et al. [47] recovered $\sim 80 \%$ of xylitol when $25 \mathrm{~g}$ of activated charcoal was added to $100 \mathrm{~mL}$ fermentation broth with $\mathrm{pH}$ adjusted to 6.0 and incubated at $80{ }^{\circ} \mathrm{C}$ for an hour. This result is inferior to the present results where lesser quantity of activated charcoal (25\% versus $5 \%)$ for xylitol purification was used. However, when different types of activated carbon were evaluated, Wei et al. [48] observed that 4\% M1 type of activated carbon was able to recover $95 \%$ xylitol with $96 \%$ decolourization. Thus, there is a scope of screening different forms of activated carbon for further improving the xylitol recovery. The xylitol recovery further reduced in the final step of alcohol precipitation step and dropped to $35-40 \%$. The same strategy used previously resulted in the recovery of $43.7 \%$ xylitol [49]. When molecular dynamic computer simulations were carried out for the binary mixture of polyols and water, Politi et al. [50] suggested that water forms an average number of $1.3 \mathrm{H}$-bonds with xylitol. However, when excess of ethanol was used for precipitation of xylitol, there is a likelihood that it not only reduced the affinity of water to form $\mathrm{H}$-bond with xylitol leading to its partial precipitation but simultaneously also formed $\mathrm{H}$-bond with xylitol resulting in its poor recoveries.

Biological production of xylitol has been studied for decades using a number of organisms including bacteria, yeasts and fungi. In general, the bioproduction of xylitol by bacteria and fungi have lower performance in comparison to yeasts. Among yeasts, Candida species are the most researched and best organisms for bioproduction of xylitol, yielding high conversion rates and productivities [51,52]. Table 4 compares the results obtained in the current work with the literature reports and large variation exists in terms of xylitol titer, yield and productivity. Most of the organisms shown in Table 4 have active xylose assimilation pathway and demonstrated incredible xylitol producing ability using xylose as a sole carbon source. Some of them have been metabolically engineered to design hyper xylitol producing cell factories. Su et al. [53] designed recombinant Escherichia coli by xylose pathway engineering and eliminating carbon catabolite repression to allow simultaneous utilization of glucose and xylose. This recombinant strain yielded $172.4 \mathrm{~g} / \mathrm{L}$ in $110 \mathrm{~h}$. Majority of the reports including current study suffers from low volumetric productivities restricting their application in a broader perspective. The use of resting cells, membrane bioreactors and fed-batch fermentation has resulted in remarkable improvement in productivities in range of 3-12 g/L h [54-56].

It is important to discuss here the report by Hallborn et al. [69] where xylitol was produced from recombinant Saccharomyces cerevisiae. S. cerevisiae and Y. lipolytica are two very different organisms; former is a conventional yeast and later is non-conventional oleaginous yeast. S. cerevisiae, exhibits a clear preference for glucose and is well adapted to assimilate it. The ability of $S$. cerevisiae to utilize glycerol is limited and therefore, the yeast is not an attractive cell factory to use glycerol, a major industrial byproduct. Contrary to $S$. cerevisiae, $Y$. lipolytica prefer glycerol over glucose and exhibits higher growth rates on glycerol than glucose [16-18]. Hallborn et al. designed the recombinant strain of $S$. cerevisiae by overexpressing xylose reductase to enable xylitol production in the yeast whereas $Y$. lipolytica used in the current work cannot grow on xylose but has the natural ability to transform of xylose to xylitol [19]. The cell biomass of recombinant $S$. cerevisiae was grown on glucose for the biotransformation of xylose to xylitol. Though the xylitol yield $(\mathrm{g} / \mathrm{g})$ obtained in both the studies were over $90 \%$, the titer achieved in current work $(53.2 \mathrm{~g} / \mathrm{L})$ was much higher than Hallborn et al. (19.0 g/L).

The Y. lipolytica strain used in the current work lacks the effective pentose pathway and require addition 
Table 4 Bioproduction of xylitol by different microorganisms

\begin{tabular}{|c|c|c|c|c|}
\hline \multirow[t]{2}{*}{ Microorganism } & \multicolumn{3}{|l|}{ Xylitol } & \multirow[t]{2}{*}{ Reference } \\
\hline & Titer (g/L) & Yield (g/g) & Productivity (g/L h) & \\
\hline Corynebacterium sp. B-4247 & 48 & 0.48 & 2.0 & {$[57]$} \\
\hline Corynebacterium glutamicum & 166 & - & 7.9 & {$[38]$} \\
\hline Escherichia coli & 172.4 & - & 1.57 & [53] \\
\hline Candida guilliermondii FTI-20037 & 77.2 & 0.74 & - & {$[58]$} \\
\hline Candida tropicalis & 131 & 0.87 & 2.91 & [59] \\
\hline Candida boidinii NRRL Y-17213 & 53.1 & 0.47 & 0.16 & {$[60]$} \\
\hline Candida sp.559-9 & 173 & 0.87 & 1.44 & {$[40]$} \\
\hline Candida athensensis SB18 & 256.5 & 0.87 & 0.97 & {$[61]$} \\
\hline Candida tropicalis CCTCC M2012462 & 38.8 & 0.70 & 0.46 & {$[62]$} \\
\hline Candida tropicalis SS2 & 220 & 0.93 & 3.3 & [55] \\
\hline Candida tropicalis KCTC 10457 & 182 & 0.85 & 12.0 & [54] \\
\hline Pichia sp. YS 54 & 25 & 0.76 & 0.50 & [63] \\
\hline Debaryomyces hansenii UFV-170 & 76.6 & 0.73 & 0.37 & [64] \\
\hline Hansunela anomala NCAIM Y.01499 & 21.7 & 0.47 & 0.23 & {$[65]$} \\
\hline Kluyveromyces marxianus CCA510 & 12.3 & 0.50 & 0.17 & {$[66]$} \\
\hline Kluyveromyces marxianus YZJ015 & 71.4 & 0.89 & 4.43 & {$[56]$} \\
\hline Hansenula polymorpha & 58 & 0.62 & 0.60 & {$[67]$} \\
\hline Saccharomyces cerevisae & 19 & 0.95 & $\sim 0.20$ & [69] \\
\hline Aspergillus niger PY11 & 1.14 & 0.101 & - & [68] \\
\hline Y. lipolytica ${ }^{a}$ & 53.2 & 0.97 & 0.32 & This study \\
\hline Y. lipolyticab & 50.5 & 0.92 & 0.30 & This study \\
\hline
\end{tabular}

a Pure glycerol as co-substrate

b Crude glycerol as co-substrate

of co-substrate for growth. The competitive titer and yield near to the theoretical demonstrates the remarkable potential of $Y$. lipolytica for xylitol production. The results obtained are better than many of existing reports. The volumetric productivity is not competitive with the best xylitol producers, but we are hopeful that it can be improved to industrial level using metabolic and process engineering approaches as mentioned above. The other advantageous feature of $Y$. lipolytica is the limited ability to cause only mild, self-limiting infections which confer the GRAS status to the yeast [70]. The main application of xylitol is in food and pharmaceutical industries, but pathogenic behaviour of most of the promising xylitol producers impedes their commercialisation. For example, Candida sp are prolific pathogens and cause globally almost $90 \%$ of fungal infections. As a result, the use of Candida sp. are prohibited in food industries [39, 40,71]. The high yield of xylitol achieved with Y. lipolytica along with its safe behaviour keep it in superior position and make it a promising microbial cell factory for xylitol production.

In the current study, the bioproduction of xylitol was coupled with two waste streams, CG, a major industrial by-product and xylose, the second major sugar present in the hemicellulosic fraction of biomass. The impurities present in CG limits its application in chemical industries as the refining costs offset the profit and because it has limited applications. For example, the large amount of CG generated in UK from biodiesel industries (Greenergy, Croda, Oil Works) has no proper use and is exported to Germany, Netherland and East Europe and sold at very low price ( $£ 40-£ 150 /$ ton). Some small manufacturers are even paying for collection of CG [72]. However, if the CG could be used locally, then environmental and economic benefits may be gained. To the best of our knowledge, this is the first study where CG was used for xylitol production. The results obtained with PG as well as CG were consistent indicating a high level of tolerance by the yeast to the impurities in CG as no inhibition was observed during the course of fermentation. These results are in agreement with many other studies where $Y$. lipolytica has been cultured on CG for the production of organic acids such citric acid, succinic acid etc. [15, 73, 74].

\section{Conclusion}

Xylitol is a platform chemical with vast commercial potential. This is the first detailed report of bioproduction of xylitol by $Y$. lipolytica. The current work 
demonstrates enormous potential of Y. lipolytica to convert xylose to xylitol with a yield near to the theoretical (>90\%). It produces similar concentrations of xylitol to some of the best xylitol producing organisms such as Candida strains. Moreover, it is a safe organism to use with GRAS status and exhibited high tolerance to CG and xylose. Employment of unconventional feedstocks as carbon sources is highly desirable for the economic viability of biorefineries and becomes a good destination for renewable carbon-rich wastes. The study demonstrated the feasibility of simultaneous valorisation of two major wastes, CG and xylose, which can be utilized as cheaper feedstocks. The strategy can be conducive towards development of a bioprocess as an alternative to the commercial chemical route and could support the sustainability of biodiesel industries/lignocellulosic biorefineries. More work is required to optimise the metabolic engineering and process scale-up to improve the economics of the bioprocess.

\section{Materials and methods}

\section{Materials}

All chemicals used in this study were of analytical grade and purchased from Sigma-Aldrich and Fisher scientific, unless stated otherwise. CG used was kindly provided by Greenergy, UK. The CG contained glycerol (72.8\%), non-glycerine material (soaps, fatty acids, esters, salts, other organic byproducts) (5.7\%), methanol (2.0\%), water (12.2\%) and ash (9.6\%). The xylose (26.4 g/L) rich SCB hydrolysate was obtained from Nova Pangea Technologies, UK.

\section{Microorganism, culture maintenance and inoculum preparation}

The current study made use of $Y$. lipolytica Po1t $\left(\mathrm{Ura}^{+}\right.$, $\mathrm{Leu}^{+}$) derived from wild-type strain W29 (ATCC20460). The Y. lipolytica strain was preserved in $20 \%$ glycerol (v/v) at $-80{ }^{\circ} \mathrm{C}$ and maintained on a petri dish containing YPD agar medium (1\% yeast extract, $2 \%$ Peptone, $2 \%$ Dextrose and $2 \%$ Agar) at $\mathrm{pH} 7.0$ and $30^{\circ} \mathrm{C}$. The seed culture was grown in a $250 \mathrm{~mL}$ Erlenmeyer flask containing
$50 \mathrm{~mL}$ YPD broth. The final $\mathrm{pH}$ of the medium prior to sterilization was adjusted to 7.0. Cultivation was carried out for $24 \mathrm{~h}$ at $30{ }^{\circ} \mathrm{C}$ on a rotary shaker at an agitation speed of 250 RPM.

\section{Submerged cultivations in shake flask}

The fermentation medium had the following composition: (g/L) PG/CG/glucose, 20; xylose, 20; yeast nitrogen base (YNB), 1.7; $\mathrm{NH}_{4} \mathrm{Cl}, 1.5$. The medium was prepared in $50 \mathrm{mM}$ phosphate buffer. The initial $\mathrm{pH}$ was adjusted to 6.8 before inoculation by using $5 \mathrm{~N} \mathrm{NaOH}$. The submerged cultivations were carried out in $500 \mathrm{~mL}$ shake flasks containing $100 \mathrm{~mL}$ working volume. The flasks were inoculated with fresh inoculum at $\mathrm{OD}_{600}$ (optical density) of 0.1 and kept at $30{ }^{\circ} \mathrm{C}$ under constant shaking at 250 RPM on a rotary shaker (Excella 24, New Brunswick).

\section{Central composite design (CCD) and artificial neural network linked genetic algorithm (ANN-GA) for media optimization}

The CCD was carried out, with the view of optimizing the variables and to give insight over the combined effect of four variables (xylose, $\mathrm{YNB}, \mathrm{NH}_{4} \mathrm{Cl}$ and phosphate buffer) at constant glycerol concentration on maximizing the production of xylitol concentration. Design-Expert software (version 7.0) was used to develop CCD for four independent variables and five levels (Table 5). The total number of experiments $(N)$ was based on Eq. (1)

$$
N=2^{k}+2 k+6
$$

where $k$ is the number of independent variables. The experiment comprised 2 axial points and 6 replicates for centre points for the evaluation of pure error. The second-order polynomial for predicting the optimal levels was expressed according to the Eq. (2).

$$
\mathrm{Y}_{i}=\beta_{0}+\sum_{i=1}^{k} \beta_{i} X_{i}+\sum_{i=1}^{k} \beta_{i i} X_{i}^{2}+\sum_{i<j} \sum \beta_{i j} X_{i} X_{j}+\varepsilon
$$

Table 5 Experimental codes, range and levels of the independent variables used for central composite design (CCD)

\begin{tabular}{|c|c|c|c|c|c|c|c|}
\hline \multirow[t]{2}{*}{ Independent variables } & \multirow[t]{2}{*}{ Units } & \multirow[t]{2}{*}{ Symbol code } & \multicolumn{5}{|c|}{ Coded value } \\
\hline & & & $+a$ & -1 & 0 & 1 & $-a$ \\
\hline Xylose & $g / L$ & $x_{1}$ & 5 & 20 & 35 & 50 & 65 \\
\hline YNB & $\%(w / v)$ & $x_{2}$ & 0.05 & 0.2 & 0.35 & 0.5 & 0.65 \\
\hline $\mathrm{NH}_{4} \mathrm{Cl}$ & $\%(w / v)$ & $x_{3}$ & 0.05 & 0.2 & 0.35 & 0.5 & 0.65 \\
\hline Phosphate buffer & $\mathrm{mM}$ & $X_{4}$ & 2.5 & 35 & 67.5 & 100 & 132.5 \\
\hline
\end{tabular}
experiments 
where, $Y_{i}$ is the Predicted response; $\beta_{0} \beta_{i}, \beta_{i j}$, $\beta_{i i}$ are constant and regression coefficients of the model, $X_{i}, X_{j}$ represent the independent variables in coded values and $\varepsilon$ represents the error.

To further optimise the media components, the artificial neural network (ANN) methodology was adapted. ANN is biological inspired model, which mimics neural system and tends to optimize non-linear systems. Multi-layer perceptron method was incorporated, and training of the network was based on feed-forward back propagation method. The network architecture consisted of four input layers (xylose, $\mathrm{YNB}, \mathrm{NH}_{4} \mathrm{Cl}$, phosphate buffer), eight hidden layers and one output layer representing xylitol concentration. In the feedforward training system, the data was channelized from input to output via., hidden layer, which was connected by parameters such as weights $(\mathrm{w})$ and biases (b). Transfer functions such as tan sigmoid (f1: tansig) and Pure linear ( $f 2$ : purelin) were situated between hidden and output layer, respectively. Tansig sums up weighted input including the biases, and the purelin carried out the linearization function for the output. The predicted output function is represented by the Eq. (3)

$$
Y_{p}=f 2\left[w^{0} \times f 1 \times\left(w^{H} \times \text { inputvector }+b^{H}\right)+b^{0}\right]
$$

where $Y_{p}$ is the predicted response, $w^{o}, b^{o}$ and $w^{H}, b^{H}$ are weights and biases of the output and hidden layer, respectively. The network training was carried out by adapting Levenberg-Marquardt (LM) backpropagation algorithm, which calculates error function based on the difference between actual output and predicted output. The algorithm was trained repeatedly until subsequent minimisation in the error between the input and output layer is met [75]. Mean squared error (MSE) was used to calculate error function using Eq. (4).

$$
M S E=\frac{1}{N} \sum_{i=1}^{N}\left(Y_{a}-Y_{p}\right)^{2}
$$

where, $Y_{a}$ is the actual output, $Y_{p}$ is the predicted output and $\mathrm{N}$ is the number of data points. The simulation of the network was carried out by in built neural network toolbox of MATLAB (version 2010a).

Genetic algorithm (GA) is a heuristic method used to determine the global optimal solution for a non-linear problem and are independent of initial values; GA is often coupled with ANN to achieve precise optimization values. GA follows four steps to find a global solution. In the first step, initialization of the solution for the population takes place followed by fitness computation. The selected individual based on the fitness computation then undergoes crossing over and mutation, creating a new set of individuals [76, 77]. This process is repeated until a global optimum value is achieved.

The trained neural network model was used as a fitness function to further optimise the input space. The schematic representation of ANN-GA algorithm for optimisation of medium components to maximize xylitol production was shown in Additional file 1: Fig S1. The objective function of GA is given by Eq. 5:

$$
\text { Maximize } Y=f(x, w), \quad x_{i}^{L} \leq x_{i} \leq x_{i}^{u}, i=1,2,3 \ldots P
$$

where $f$ is the objective function (ANN model), $x$ denotes input vector, $\mathrm{w}$ denotes corresponding weight vector, $\mathrm{Y}$ refers to the xylitol experimental yield, $\mathrm{X}$ denotes operating conditions, $P$ denotes number of input variables, $x_{i}^{L} \&$ $x_{i}^{U}$ are lower and upper bounds of $x_{i}$ fitness of each candidate solution.

\section{Model validation under shake flask conditions}

The integration of CCD and ANN-GA predicted some crucial parameters and their concentrations, which could give optimum xylitol yields. Therefore, it became essential to validate the predicted values at shake flask level based on the global optimum values obtained by ANNGA training. Shake flask studies were conducted with PG as co-substrate. However, simultaneously the efficacy of Y. lipolytica Polt $\left(\mathrm{Ura}^{+} \mathrm{Leu}^{+}\right)$using co-substrate combinations namely PG + xylose rich SCB hydrolysate and CG + pure xylose was also evaluated to assess the tolerance, utilization and biovalorization ability of the said strain for carbon sources derived from renewable feedstock.

\section{Batch cultivation in bioreactor}

The batch experiments were performed in a $2.5 \mathrm{~L}$ bioreactor (Electrolab Bioreactors, UK) with $1.0 \mathrm{~L}$ working volume. The inoculum was prepared using optimised media and the optimum values of media components were as follows (g/L): PG/CG, 20; xylose, 55; YNB, 5.0; $\mathrm{NH}_{4} \mathrm{Cl}$, 3.94; phosphate buffer, $132.5 \mathrm{mM}$. The starting $\mathrm{pH}$ was 6.8 and not controlled during the fermentation. The temperature and agitation speed were controlled at $30{ }^{\circ} \mathrm{C}$ and $250 \mathrm{RPM}$, respectively, while the aeration rate was maintained at $2.0 \mathrm{~L} / \mathrm{min}$ for initial $48 \mathrm{~h}$ and then changed to $1.0 \mathrm{~L} / \mathrm{min}$ for the rest of fermentation period.

\section{Biotransformation by resting cells}

For active cells, $Y$. lipolytica was grown on optimised medium with PG in $500 \mathrm{~mL}$ flasks containing with $20 \%$ working volume. The temperature, $\mathrm{pH}$ and agitation speed were maintained at $30^{\circ} \mathrm{C}, 6.8$ and $250 \mathrm{RPM}$, respectively. For the second stage (biotransformation), the cells were harvested in the late exponential period 
(after $48 \mathrm{~h}$ ) when the $\mathrm{OD}_{600}$ was somewhere between 20 and 25 . Immediately after, the culture was centrifuged at $2800 \times g$ for $10 \mathrm{~min}$, and the resulting pellet was washed with ice-cold $100 \mathrm{mM}$ phosphate buffer ( $\mathrm{pH}$ 7.0). The cells were resuspended in a bioconversion medium containing xylose (30, 70 and $100 \mathrm{~g} / \mathrm{L}$ ) in phosphate buffer (100 mM). The bioconversion experiments were carried out at $30^{\circ} \mathrm{C}$ with freshly prepared biomass.

\section{Downstream processing of xylitol}

The purification protocol for xylitol was performed according to Rivas et al. [78]. The $100 \mathrm{~mL}$ of spent fermentation broth was subjected to centrifugation at $20,000 \times g$ to separate the cells and the clarified broth was treated with $5 \%$ activated charcoal. The charcoal treated broth was precipitated by adding four volume of absolute ethanol and incubated at $4{ }^{\circ} \mathrm{C}$ for $1 \mathrm{~h}$. After $1 \mathrm{~h}$, the precipitates were removed by centrifuging the mixture at $4000 \times g$ for $10 \mathrm{~min}$. The supernatant was vacuum concentrated at $40{ }^{\circ} \mathrm{C}$. The concentrated sample and ethanol were mixed at a ratio of $1: 4$ and incubated at $-20^{\circ} \mathrm{C}$ with slight agitation (50 RPM) until crystals were observed. To improve the crystallization about $1 \mathrm{~g} / \mathrm{L}$ of xylitol was mixed with the concentrated sample.

\section{Analytical methods}

The samples were withdrawn periodically and analysed for OD, $\mathrm{pH}$, residual glycerol/glucose, xylose and xylitol. Cell growth was quantified by measuring the optical density at $600 \mathrm{~nm}$ wavelength in a $1 \mathrm{~mm}$-path-length cuvette using a double beam spectrophotometer (Jenway 6310, UK). One unit of absorbance at $600 \mathrm{~nm}$ corresponded to a cell dry weight $(\mathrm{CDW})$ of $0.21 \mathrm{~g} / \mathrm{L}$. The concentrations of glycerol, glucose, xylose and xylitol were measured by high performance liquid chromatography (Agilent Technologies 1200 series, USA). The supernatants, obtained by centrifugation of the culture samples at $10,000 \times g$ for $10 \mathrm{~min}$, were filtered through a $0.22 \mu \mathrm{m}$ PVDF membrane (Sartorious, Germany) and eluted using Rezex ROA-Organic Acid $\mathrm{H}+\left(\right.$ Phenomenex, USA) column at $60{ }^{\circ} \mathrm{C}$ attached with refractive index detector (RID). The mobile phase and flow rate were $0.5 \mathrm{mM} \mathrm{H}_{2} \mathrm{SO}_{4}$ and $0.4 \mathrm{~mL} / \mathrm{min}$, respectively. All measurements were conducted in triplicates and the values were averaged. The standard deviation was not more than $10 \%$.

\section{Supplementary information}

Supplementary information accompanies this paper at https://doi. org/10.1186/s12934-020-01378-1.

Additional file 1: Figure S1. Schematic representation of ANN-GA for achieving the global optimum value for the maximization of xylitol concentration from Y. lipolytica. Table S1. Statistical measures and performance of the ANN model for training, testing, validation and all data.

\section{Acknowledgements}

We are grateful to CBMNet and Ineuvo Ltd for funding this work. The authors express gratitude to BBSRC, Innovate UK and Department of Biotechnology, India for funding the vWa Project (Grant R1954CCE). We are thankful to Cranfield University for providing facilities for conducting experiments. We acknowledge our industrial partner, Nova Pangaea Technologies and Biodiesel company Greenergy, UK for providing xylose rich SCB hydrolysate and crude glycerol, respectively for this work.

\section{Authors' contributions}

AAP and DJT carried out all the experimental work. VK analyzed the data and wrote the manuscript. GAL, AM, CV-V, FC and DA were involved in proof reading the manuscript. RLA provided useful suggestions for experimental design and revised the manuscript critically. All authors read and approved the final manuscript.

\section{Funding}

The vWa Project (Grant R1954CCE) is funded by the BBSRC, Innovate UK and Department of Biotechnology. The Master study of DJT is supported through funding from CBMNet and Inevo Ltd. The funders had no role in study design, data collection and analysis, decision to publish, or preparation of the article.

\section{Availability of data and materials}

All data generated and analysed during this study are included in this published article and its additional files.

Ethics approval and consent to participate

Not applicable.

\section{Consent for publication}

Not applicable.

\section{Competing interests}

The authors declare that they have no competing interests.

\section{Author details}

1 School of Water, Energy and Environment, Cranfield University, Cranfield MK43 OAL, UK. ${ }^{2}$ Department of Bioengineering and Imperial College Centre for Synthetic Biology, Imperial College London, London SW7 2AZ, UK. ${ }^{3}$ School of Chemical Engineering, University of Birmingham, Birmingham B15 2TT, UK. ${ }^{4}$ Biochemistry and Biotechnology Area, Material Resource Efficiency Division, CSIR-Indian Institute of Petroleum, Mohkampur, Dehradun 248005, India.

Received: 23 March 2020 Accepted: 25 May 2020

Published online: 03 June 2020

\section{References}

1. Nizami AS, Rehan M, Waqas M, Naqvi M, Ouda OKM, Shahzad K, et al. Waste biorefineries: enabling circular economies in developing countries. Bioresour Technol. 2017:241:1101-17.

2. Naik SN, Goud W, Rout PK, Dalai AK. Production of first and second generation biofuels: a comprehensive review. Renew Sustain Energy Rev. 2010;14:578-97.

3. Menon V, Rao M. Trends in bioconversion of lignocellulose: biofuels, platform chemicals \& biorefinery concept. Prog Energy Combust Sci. 2012:38:522-50.

4. Bozell JJ, Petersen GR. Technology development for the production of biobased products from biorefinery carbohydrates-The US Department of Energy's "top 10" revisited. Green Chem. 2010;12:539-54.

5. Ur-Rehman S, Mushtaq Z, Zahoor T, Jamil A, Murtaza MA. Xylitol: a review on bioproduction, application, health benefits, and related safety issues. Crit Rev Food Sci Nutr. 2015;55:1514-28.

6. Delgado Arcaño Y, Valmaña García OD, Mandelli D, Carvalho WA, Magalhães Pontes LA. Xylitol: a review on the progress and challenges of its production by chemical route. Catal Today. 2020;344:2-14.

7. Gao M, Ploessl D, Shao Z. Enhancing the co-utilization of biomass-derived mixed sugars by yeasts. Front Microbiol Front Media. 2019;10:3264. 
8. Gírio FM, Carvalheiro F, Duarte LC, Bogel-Łukasik R. Deconstruction of the hemicellulose fraction from lignocellulosic materials into simple sugars. In: da Silva S, Chandel A, editors. D-Xylitol Ferment. Berlin, Heidelberg: Springer; 2012. p. 3-37.

9. Mussatto S, Dragone GM. Biomass pretreatment, biorefineries, and potential products for a bioeconomy development. In: Mussatto SI, editor. Biomass Fractionation Technologies for a lignocellulosic feedstock based biorefinery. Amsterdam, Netherlands: Elsevier; 2016. p. 1-22.

10. Kumar V, Park S. Potential and limitations of Klebsiella pneumoniae as a microbial cell factory utilizing glycerol as the carbon source. Biotechnol Adv. 2018;36:150-67.

11. European Biodiesel Board. 2020. https://www.ebb-eu.org/stats.php.

12. Werpy T, Petersen G, Aden A, Bozell J, Holladay J, White J, Manheim A, Elliot D, Lasure L, Jones S, Gerber M, Ibsen K, Lumberg L, Kelley S. Top value added chemicals from biomass - volume 1: results of screening for potential candidates from sugars and synthesis gas. Washington, DC: Pacific Northwest National Laboratory, National Renewable Energy Laboratory and Department of Energy; 2004. p. 76.

13. de Albuquerque TL, Da Silva IJ, De MacEdo GR, Rocha MVP. Biotechnological production of xylitol from lignocellulosic wastes: a review. Process Biochem. 2014;49:1779-89.

14. Dasgupta D, Bandhu S, Adhikari DK, Ghosh D. Challenges and prospects of xylitol production with whole cell bio-catalysis: a review. Microbiol Res. 2017;197:9-21.

15. Liu HH, Ji XJ, Huang H. Biotechnological applications of Yarrowia lipolytica: past, present and future. Biotechnol Adv. 2015;33:1522-46.

16. Workman M, Holt P, Thykaer J. Comparing cellular performance of Yarrowia lipolytica during growth on glucose and glycerol in submerged cultivations. AMB Express. 2013;3:1-9.

17. Ledesma-Amaro R, Nicaud JM. Metabolic engineering for expanding the substrate range of Yarrowia lipolytica. Trends Biotechnol. 2016;34:798-809.

18. Lubuta P, Workman M, Kerkhoven EJ, Workman CT. Investigating the influence of glycerol on the utilization of glucose in Yarrowia lipolytica using RNA-Seq-based transcriptomics. G3 Genes Genomes Genet. 2019:9:4059-71.

19. Ledesma-Amaro R, Lazar Z, Rakicka M, Guo Z, Fouchard F, Le Coq AMC, et al. Metabolic engineering of Yarrowia lipolytica to produce chemicals and fuels from xylose. Metab Eng. 2016;38:115-24.

20. Rodriguez GM, Hussain MS, Gambill L, Gao D, Yaguchi A, Blenner M. Engineering xylose utilization in Yarrowia lipolytica by understanding its cryptic xylose pathway. Biotechnol Biofuels. 2016;9:149.

21. Prabhu AA, Purkayastha A, Mandal B, Kumar JP, Mandal BB, Veeranki VD. A novel reverse micellar purification strategy for histidine tagged human interferon gamma (hIFN- $\gamma$ ) protein from Pichia pastoris. Int J Biol Macromol. 2018;107:2512-24.

22. Unni S, Prabhu AA, Pandey R, Hande R, Veeranki VD. Artificial neural network-genetic algorithm (ANN-GA) based medium optimization for the production of human interferon gamma (hIFN- - ) in Kluyveromyces lactis cell factory. Can J Chem Eng. 2019;97:843-58.

23. Prabhu AA, Gadela R, Bharali B, Deshavath NN, Dasu VV. Development of high biomass and lipid yielding medium for newly isolated Rhodotorula mucilaginosa. Fuel. 2019;239:874-85.

24. Samul D, Leja K, Grajek W. Impurities of crude glycerol and their effect on metabolite production. Ann Microbiol. 2014;64:891-8.

25. Converti A, Domínguez JM. Influence of temperature and $\mathrm{pH}$ on xylitol production from xylose by Debaryomyces hansenii. Biotechnol Bioeng. 2001;75:39-45.

26. Moreno AD, Carbone A, Pavone R, Olsson L, Geijer C. Evolutionary engineered Candida intermedia exhibits improved xylose utilization and robustness to lignocellulose-derived inhibitors and ethanol. Appl Microbiol Biotechnol. 2019;103:1405-16.

27. Niehus X, Crutz-Le Coq A-M, Sandoval G, Nicaud J-M, Ledesma-Amaro R Engineering Yarrowia lipolytica to enhance lipid production from lignocellulosic materials. Biotechnol Biofuels. 2018;11:11.

28. Jönsson L, Martín C. Pretreatment of lignocellulose: formation of inhibitory by-products and strategies for minimizing their effects. Bioresour Technol. 2016;199:103-12

29. Ko BS, Kim J, Kim JH. Production of xylitol from D-xylose by a xylitol dehydrogenase gene-disrupted mutant of Candida tropicalis. Appl Environ Microbiol. 2006;72:4207-13.
30. Pappu JSM, Gummadi SN. Multi response optimization for enhanced xylitol production by Debaryomyces nepalensis in bioreactor. 3 Biotech. 2016:6:1-10.

31. Kumar V, Sankaranarayanan M, Jae KE, Durgapal M, Ashok S, Ko Y, et al. Co-production of 3-hydroxypropionic acid and 1,3-propanediol from glycerol using resting cells of recombinant Klebsiella pneumoniae J2B strain overexpressing aldehyde dehydrogenase. Appl Microbiol Biotechnol. 2012;96:373-83.

32. Carballeira JD, Quezada MA, Hoyos P, Simeó Y, Hernaiz MJ, Alcantara $A R$, et al. Microbial cells as catalysts for stereoselective red-ox reactions. Biotechnol Adv. 2009;27:686-714.

33. de Carvalho CCCR. Enzymatic and whole cell catalysis: finding new strategies for old processes. Biotechnol Adv. 2011;29:75-83.

34. Martínez EA, Canettieri EV, Bispo JAC, Giulietti M, DeAlmeidaSilva JB, Converti A. Strategies for xylitol purification and crystallization: a review. Sep Sci Technol. 2015:50:2087-98.

35. Unrean P, Ketsub N. Integrated lignocellulosic bioprocess for co-production of ethanol and xylitol from sugarcane bagasse. Ind Crops Prod. 2018;123:238-46.

36. Akinterinwa O, Khankal R, Cirino PC. Metabolic engineering for bioproduction of sugar alcohols. Curr Opin Biotechnol. 2008;19:461-7.

37. Pal S, Choudhary V, Kumar A, Biswas D, Mondal AK, Sahoo DK. Studies on xylitol production by metabolic pathway engineered Debaryomyces hansenii. Bioresour Technol. 2013;147:449-55.

38. Sasaki M, Jojima T, Inui M, Yukawa H. Xylitol production by recombinant Corynebacterium glutamicum under oxygen deprivation. Appl Microbiol Biotechnol. 2010:86:1057-66.

39. Mohamad NL, Mustapa Kamal SM, Mokhtar MN. Xylitol biological production: a review of recent studies. Food Rev Int. 2015;31:74-89.

40. Ikeuchi T, Azuma M, Kato J, Ooshima H. Screening of microorganisms for xylitol production and fermentation behavior in high concentrations of xylose. Biomass Bioenerg. 1999;16:333-9.

41. Jeon WY, Yoon BH, Ko BS, Shim WY, Kim JH. Xylitol production is increased by expression of codon-optimized Neurospora crassa xylose reductase gene in Candida tropicalis. Bioprocess Biosyst Eng. 2012;35:191-8.

42. Gao C, Yang X, Wang H, Rivero CP, Li C, Cui Z, et al. Robust succinic acid production from crude glycerol using engineered Yarrowia lipolytica. Biotechnol Biofuels. 2016;9:179.

43. Pappu SMJ, Gummadi SN. Artificial neural network and regression coupled genetic algorithm to optimize parameters for enhanced xylitol production by Debaryomyces nepalensis in bioreactor. Biochem Eng J. 2017;120:136-45.

44. Prabhu AA, Mandal B, Dasu W. Medium optimization for high yield production of extracellular human interferon- $\gamma$ from Pichia pastoris: a statistical optimization and neural network-based approach. Korean J Chem Eng. 2017;34:1109.

45. Xia Y, Yu X, Tsao GT. Identification of required nutrient components of yeast nitrogen base for Candida shehatae ATTCC 22984 fermenting xylose to ethanol. Biotechnol Lett. 1995;17:161-6.

46. Morais Junior WG, Pacheco TF, Trichez D, Almeida JRM, Gonçalves SB. Xylitol production on sugarcane biomass hydrolysate by newly identified Candida tropicalis JA2 strain. Yeast. 2019:36:349-61.

47. Gurgel PV, Mancilha IM, Peçanha RP, Siqueira JFM. Xylitol recovery from fermented sugarcane bagasse hydrolyzate. Bioresour Technol. 1995;52:219-23.

48. Wei J, Yuan Q, Wang T, Wang L. Purification and crystallization of xylitol from fermentation broth of corncob hydrolysates. Front Chem Eng China. 2010;4:57-64

49. Mussatto SI, Santos JC, Ricardo Filho WC, Silva SS. A study on the recovery of xylitol by batch adsorption and crystallization from fermented sugarcane bagasse hydrolysate. J Chem Technol Biotechnol. 2006;81:1840-5.

50. Politi R, Sapir L, Harries D. The impact of polyols on water structure in solution: a computational study. J Phys Chem A. 2009;1 13:7548-55.

51. Granström TB, Izumori K, Leisola M. A rare sugar xylitol. Part l: The biochemistry and biosynthesis of xylitol. Appl Microbiol Biotechnol. 2007;74:277-81.

52. Rao RS, Jyothi CP, Prakasham RS, Rao CS, Sarma PN, Rao LV. Strain improvement of Candida tropicalis for the production of xylitol: biochemical and physiological characterization of wild-type and mutant strain CT-OMV5. J Microbiol. 2006;44:113-20.

53. Su B, Wu M, Zhang Z, Lin J, Yang L. Efficient production of xylitol from hemicellulosic hydrolysate using engineered Escherichia coli. Metab Eng. 2015;31:112-22. 
54. Kwon SG, Park SW, Oh DK. Increase of xylitol productivity by cell-recycle fermentation of Candida tropicalis using submerged membrane bioreactor. J Biosci Bioeng. 2006;101:13-8.

55. Jeon YJ, Shin H-S, Rogers PL. Xylitol production from a mutant strain of Candida tropicalis. Lett Appl Microbiol. 2011;53:106-13.

56. Zhang J, Zhang B, Wang D, Gao X, Hong J. Xylitol production at high temperature by engineered Kluyveromyces marxianus. Bioresour Technol. 2014;152:192-201

57. Rangaswamy S, Agblevor FA. Screening of facultative anaerobic bacteria utilizing $\mathrm{D}$-xylose for xylitol production. Appl Microbiol Biotechnol. 2002;60:88-93.

58. Barbosa MFS, de Medeiros MB, de Mancilha IM, Schneider H, Lee H. Screening of yeasts for production of xylitol from D-xylose and some factors which affect xylitol yield in Candida guilliermondii. J Ind Microbiol. 1988;3:241-51.

59. Oh DK, Kim SY. Increase of xylitol yield by feeding xylose and glucose in Candida tropicalis. Appl Microbiol Biotechnol. 1998;50:419-25.

60. Vandeska E, Amartey S, Kuzmanova S, Jeffries T. Effects of environmental conditions on production of xylitol by Candida boidinii. World J Microbio Biotechnol. 1995;11:213-8.

61. Zhang J, Geng A, Yao C, Lu Y, Li Q. Xylitol production from d-xylose and horticultural waste hemicellulosic hydrolysate by a new isolate of Candida athensensis SB18. Bioresour Technol. 2012;105:134-41.

62. Ping $Y$, Ling $H Z$, Song G, Ge JP. Xylitol production from non-detoxified corncob hemicellulose acid hydrolysate by Candida tropicalis. Biochem Eng J. 2013;75:86-91.

63. Rao RS, Bhadra B, Shivaji S. Isolation and characterization of xylitolproducing yeasts from the gut of colleopteran insects. Curr Microbiol. 2007;55:441-6.

64. Sampaio FC, Torre P, LopesPassos FM, Perego P, VieiraPassos FJ, Converti A. Xylose Metabolism in Debaryomyces hansenii UFV-170. Effect of the specific oxygen uptake rate. Biotechnol Prog. 2004;20:1641-50.

65. Mareczky Z, Fehér A, Fehér C, Barta Z, Réczey K. Effects of pH and aeration conditions on xylitol production by Candida and Hansenula yeasts. Period Polytech Chem Eng. 2016;60:54-9.

66. de Albuquerque TL, Gomes SDL, Marques JE, da Silva IJ, Rocha MVP. Xylitol production from cashew apple bagasse by Kluyveromyces marxianus CCA510. Catal Today. 2015;255:33-40.

67. Suryadi H, Katsuragi T, Yoshida N, Suzuki S, Tani Y. Polyol production by culture of methanol-utilizing yeast. J Biosci Bioeng. 2000;89:236-40.

68. Kang TZ, Mohammad SH, Murad AMA, Illias RM, Jahim JM. Fermentative production of xylitol: a first trial on xylose bifurcation. Ind. J. Sci. Technol. 2016;9:1-5.
69. Hallborn J, Walfridsson M, Airaksinen U, Ojamo H, Hahn-Hägerdal B, Penttilä $M$, et al. Xylitol production by recombinant Saccharomyces cerevisiae. Nat Biotechnol. 1991;9:1090-5.

70. Abdel-Mawgoud AM, Markham KA, Palmer CM, Liu N, Stephanopoulos G, Alper HS. Metabolic engineering in the host Yarrowia lipolytica. Metab Eng. 2018;50:192-208.

71. Turner SA, Butler G. The Candida pathogenic species complex. Cold Spring Harb Perspect Med. 2014;4:a019778.

72. Zoannaou KS, Adebanjo D, Lin Y, Harvey P. Glycerol Fuel Supply Chain, University of Greenwich.2013.

73. Rywińska A, Juszczyk P, Wojtatowicz M, Robak M, Lazar Z, Tomaszewska L, et al. Glycerol as a promising substrate for Yarrowia lipolytica biotechnological applications. Biomass Bioenerg. 2013;48:148-66.

74. Yovkova V, Otto C, Aurich A, Mauersberger S, Barth G. Engineering the a-ketoglutarate overproduction from raw glycerol by overexpression of the genes encoding NADP +-dependent isocitrate dehydrogenase and pyruvate carboxylase in Yarrowia lipolytica. Appl Microbiol Biotechnol. 2014;98:2003-13.

75. Mandal B, Prabhu A, Pakshirajan K, Veeranki Dasu V. Construction and parameters modulation of a novel variant Rhodococcus opacus BM985 to achieve enhanced triacylglycerol-a biodiesel precursor, using synthetic dairy wastewater. Process Biochem. 2019;84:9-21.

76. Yasin Y, Ahmad FBH, Ghaffari-Moghaddam M, Khajeh M. Application of a hybrid artificial neural network-genetic algorithm approach to optimize the lead ions removal from aqueous solutions using intercalated tartrateMg-Al layered double hydroxides. Environ Nanotechnol Monit Manag. 2014;1-2:2-7.

77. Sushma C, Anand AP, Veeranki VD. Enhanced production of glutaminase free L-asparaginase II by Bacillus subtilis WB800N through media optimization. Korean J Chem Eng. 2017;34:2901-15.

78. Rivas B, Torre P, Domínguez JM, Converti A, Parajó JC. Purification of xylito obtained by fermentation of corncob hydrolysates. J Agric Food Chem. 2006:54:4430-5.

\section{Publisher's Note}

Springer Nature remains neutral with regard to jurisdictional claims in published maps and institutional affiliations.
Ready to submit your research? Choose BMC and benefit from:

- fast, convenient online submission

- thorough peer review by experienced researchers in your field

- rapid publication on acceptance

- support for research data, including large and complex data types

- gold Open Access which fosters wider collaboration and increased citations

- maximum visibility for your research: over 100M website views per year

At BMC, research is always in progress.

Learn more biomedcentral.com/submissions 